\title{
Novice Explanations Of Hurricane Formation Offer Insights Into Scientific Literacy And The Development Of Expert-Like Conceptions
}

Leilani A. Arthurs, University of Nebraska-Lincoln, USA

Matthew S. Van Den Broeke, University of Nebraska-Lincoln, USA

\begin{abstract}
The ability to explain scientific phenomena is a key feature of scientific literacy, and engaging students' prior knowledge, especially their alternate conceptions, is an effective strategy for enhancing scientific literacy and developing expertise. The gap in knowledge about the alternate conceptions that novices have about many of Earth's complex phenomena (National Research Council, 2012), however, makes this type of engagement in geoscience courses challenging. This study helps to fill this gap by identifying and describing how novices to geoscience explain a complex scientific phenomenon, hurricane formation. Using a pragmatism methodology, 326 students in introductory-level geoscience courses at two public universities in the United States of America, in Georgia ( $n=168$ ) and Nebraska ( $n=158)$, were surveyed. The questionnaire was designed to target and collect novices' explanations of a single complex Earth phenomenon - hurricane formation. Constant comparative analyses of textual content and diagrams revealed a variety of alternate conceptions. The data suggests that novices seldom invoke scientific first principles, which students matriculating through the education system are expected to learn before college, in their explanations. Two theoretical models synthesize the alternate conceptions and illustrate pathways of conceptual change along which students might move from more novice-like to more expert-like ways of scientific thinking. Our findings provide a basis for the development of instructional activities that aid students in developing more expertlike conceptions of hurricane formation and other complex Earth phenomena.
\end{abstract}

Keywords: Geoscience Education Research; Meteorology Education; Scientific Literacy; Misconceptions; NoviceTo-Expert; Conceptual Change

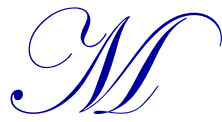

any people in the United States of America (USA) are directly or indirectly impacted by natural hazards, such as hurricanes (Dash \& Gladwin, 2007; Dow \& Cutter, 2000; Lazo, et al., 2010; Morss \& Hayden, 2010; Simms, et al., 2013; Zhang et al., 2007). Few studies, however, document how laypeople explain these phenomena. The ability to explain scientific phenomena is a key feature of scientific literacy (Organization for Economic Co-Operation and Development [OECD], 2006).

A strategy for advancing scientific literacy through classroom instruction involves engaging students' prior knowledge, especially their alternate conceptions, in the learning process (Bransford et al., 1999). However, a barrier to implementing this strategy in geoscience courses is the gap in knowledge about the alternate conceptions that students have about many of Earth's complex phenomena and processes (National Research Council, 2012). A broader and deeper understanding of students' alternate conceptions could be used to facilitate their learning and development towards more expert-like ways of scientific thinking and reasoning.

This is an exploratory study that uses a pragmatism methodology (Creswell, 2003) to address the aforementioned gap in knowledge. More specifically, this study focuses on student explanations of the scientific phenomenon of hurricane formation. Consistent with the pragmatism methodology, this study is done for the express purpose of continued research that builds on its findings (e.g., Chang \& Linn, 2013; Opfer, et al., 2012; Parham, et al., 2010), such as Copyright by author(s); $\underline{\text { CC-BY }}$ 
developing and testing assessment items dealing with hurricane formation that can be used in introductory-level college geoscience courses. With this in mind, the present study addresses two questions:

i. How do novices to geoscience explain a complex scientific phenomenon, hurricane formation, prior to formal instruction on the subject?

ii. How do the explanations of novices to geoscience contrast with one another and with an expert-defined explanation used in introductory-level college geoscience courses?

In this study, we define novices to geoscience as persons who are just starting to learn about geoscience. To answer our research questions, a short, paper-based, open-ended questionnaire was administered to over 300 students enrolled in introductory-level college geoscience courses at two large Ph.D. granting, research extensive universities in the United States of America (USA), in Georgia $(n=168)$ and Nebraska $(n=158)$. Their responses were subjected to textual content analyses and diagrammatic analysis, and they were compared and contrasted with an expert-defined explanation pitched at the mastery level for an introductory-level college geoscience course.

\section{BACKGROUND AND THEORETICAL PERSPECTIVES}

\section{Scientific Literacy}

Scientific literacy is a concept that is integral to developing an informed international citizenry that is equipped to address life situations in which science plays a key role (Bybee et al., 2009). Wysession (2012) discusses key literacy documents produced through geoscience community efforts that are relevant to those who teach about Earth phenomena in the USA. They include the Earth Science Literacy Principles (Wysession et al., 2009), the Essential Principles of Ocean Literacy (Carley et al., 2013), Essential Principles and Fundamental Concepts for Atmospheric Science Literacy (Johnson et al., 2009), and Essential Principles of Climate Science (US Global Change Research Program, 2009). These documents define an Earth-science literate person as one who understands the essential principles of the Earth system, knows how to assess scientifically credible information about the Earth system, communicates about the Earth system in a meaningful way, and is able to make informed and responsible decisions regarding actions that may affect the Earth system.

For the Program for International Student Assessment (PISA), the OECD (2006) defines scientific literacy as being characterized by four interrelated features of an individual's: (i) scientific knowledge and use of that knowledge to identify questions, to acquire new knowledge, to explain scientific phenomenon, and to draw evidence-based conclusions about science-related issues; (ii) understanding of the characteristic features of science as a form of human knowledge and enquiry; (iii) awareness of how science and technology shape our material, intellectual, and cultural environments; and (iv) willingness to engage in science-related issues, and with the ideas of science, as a constructive, concerned, and reflective citizen. In this exploratory study, we are particularly focused on students' ability to explain scientific phenomena, using the example of how hurricanes form.

Hurricanes, more broadly referred to as tropical cyclones, are Earth phenomena that can present themselves as natural hazards to citizens in the USA. For example, in 2005 alone, four major hurricanes made landfall in the USA, causing more than 2,000 deaths and $\$ 100$ billion in damage (National Climatic Data Center \& National Oceanic and Atmospheric Administration, 2013). Figure 1 illustrates hurricane tracks near to and in the USA between 1993 and 2012. Hurricanes are phenomena that have relevance to not only citizens living in these areas but also to citizens across the nation because they can result in weighty costs (National Climatic Data Center \& National Oceanic and Atmospheric Agency, 2013; Wuebbles et al., 2014). In the USA, taxes that citizens pay support disaster relief efforts such as the Heartland and Hurricane Ike Disaster Relief Act and the Natural Disaster Relief Act (Internal Revenue Service, 2009). As such, taxpayers' and laypersons' knowledge of how, where, and when natural disasters like hurricanes can facilitate informed decision making about how to prepare for (e.g., where to live or how to protect against the impacts of natural disasters) and how to respond to natural disasters after they occur (e.g., short-term support and long-term legislative acts). 
Figure 1. Map of hurricane tracks that affected the USA during the period 1993-2012 generated using the Historical Hurricane Tracks tool provided by the National Oceanic and Atmospheric Administration (https://coast.noaa.gov/hurricanes/). Curved lines overlaying the map represent hurricane tracks. The states in which participants were surveyed, Nebraska and Georgia, are outlined with thick white borders. The time frame shown on the map represents the time relevant to participants in the study.

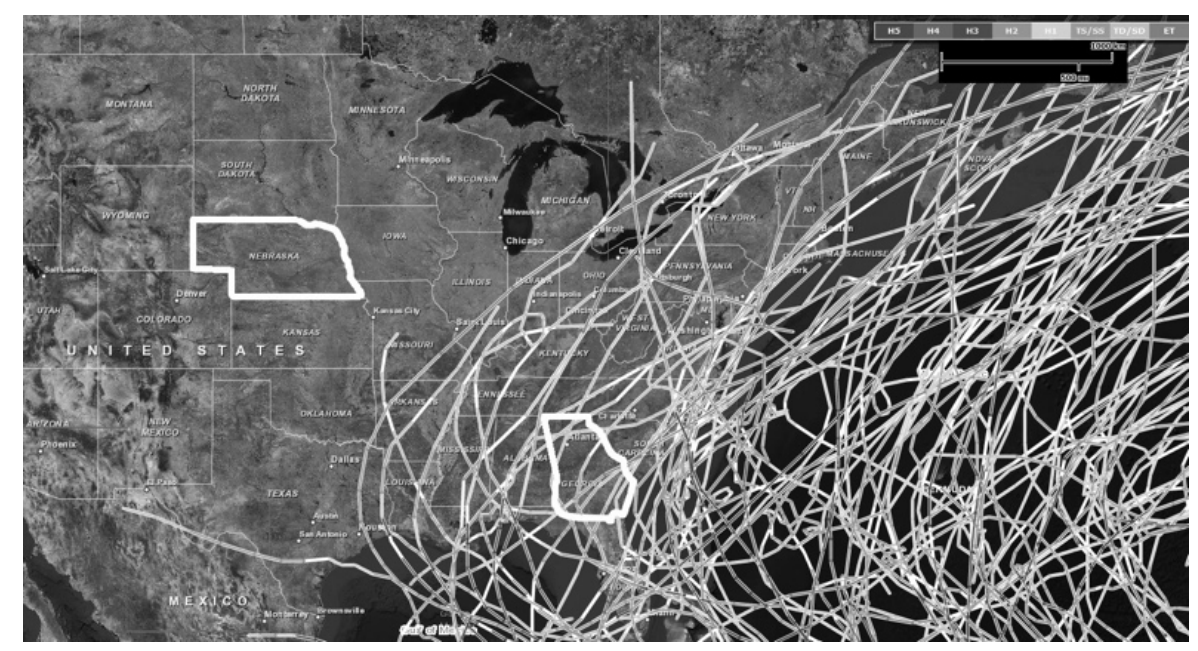

Hurricane formation was selected as the subject for studying novice explanations of a scientific phenomenon for three main reasons: (i) hurricanes are relevant to real-life situations that citizens in the USA experience directly and indirectly, (ii) the subject of hurricanes is relevant to and taught in introductory-level college geoscience courses, and (iii) hurricanes are an example of a complex Earth phenomenon that can be explained in terms of scientific first principles. Citing Aristotle, Gasser-Wingate (2016) defines first principles as propositions that are "necessary and explanatorily primitive truths from which all our scientific understanding is derived" (p. 2). For this study, we similarly define scientific first principles as fundamental or basic scientific concepts that represent abstract scientific knowledge, such as chemical and physical processes, that can be applied to explain more complex phenomena.

\section{Alternate Conceptions and Cognitive Models}

Alternate conceptions are discussed in the literature as existing along a spectrum from novice-like ideas to expert-like ideas (Bereiter \& Scardamalia, 1986; Lindblom-Ylanne \& Lonka, 2001; Wieman \& Perkins, 2005; Wieman 2007) or along a spectrum from non-scientific to scientific ideas (Izquierdo-Aymerich \& Aduriz-Bravo, 2003; Libarkin et al., 2005; Mortimer, 1995). The idea of alternate conceptions is not new and others refer to these types of conceptions as misconceptions (Capps et al., 2013; Helm, 1980), alternate frameworks (Dal, 2007; Driver, 1981), preconceptions (Clement 1993; Novak, 1977), naïve ideas (Clement, 1993; Kinchin et al., 2000; Reiner et al., 2000), and folk theories (Lakoff, 1987). The terminology used in the literature to discuss the idea of alternate conceptions is used inconsistently and ambiguously. This is, in part, due to a lack of a common language with which to discuss these ideas. In the present study, an alternate conception is defined as an idea or thought held by a student at any point in time relative to the instructional period of interest, formed by direct or inferred experience, and is more/less scientifically accurate and complete (Arthurs, 2011). The constructivist theory of learning is widely accepted today and states that people's prior knowledge and experiences, including their alternate conceptions, play a pivotal role in their learning process (Bransford et al., 1999) by helping or hindering the process of conceptual change (Bransford et al., 1999; Murphy, 2007; Vosniadou \& Brewer, 1992) that leads toward greater expertise.

For this study, we refer to student-held ideas influenced by prior experience and knowledge as alternate conceptions or cognitive models. Individuals hold certain cognitive models that explain how the world around them operates. These cognitive models are based on everyday life experiences and assumptions that people generally accept to be true, and they may be incongruent with the equivalent scientific theories held by contemporary experts. 
Novices' alternate conceptions often disagree with accepted scientific conceptions held by experts and play a central role in the learning process. As such, integrating them into instructional activities can help facilitate students' learning and their development towards more expert-like thinking. This type of integration of alternate conceptions into instruction is well aligned with a constructivist approach to teaching and learning (Bransford et al., 1999; Shell et al., 2010). In order to integrate students' alternate conceptions into instruction (including formative and summative assessments), it is necessary to first understand what they already know about a particular topic prior to formal instruction. In keeping with the pragmatism methodology (Creswell, 2003), the findings of this study will be used for further research for the development and testing of items that can be used in formative and summative assessments for use in introductory-level college geoscience courses that teach about hurricanes and their formation.

\section{Evidence of Cognition and Syntax for Framing Cognitive Models}

Although integrating alternate conceptions into teaching is an accepted means to facilitate learning, identifying individuals' alternate conceptions is a challenge because ascertaining what people think does not lend itself to traditional models of quantitative scientific inquiry. Methods that utilize language (Dixon, 1982; Lakoff, 1987; Rosch, 1975, 1981) and concept sketches (Johnson \& Reynolds, 2005; Reusser et al., 2012; Smith \& Bermea, 2012) provide a means to do so. Lakoff (1987) and his predecessors discuss three ideas that frame this study. First, the domain of experience is where human cognition lies. Second, individual interactions with the physical world and with language itself construct an individual's domain of experience. Third, examination of the domain of experience and linguistic evidence provides insight into human cognition. We elaborate on this third point to also include concept sketches as representations of individuals' cognitive models (Ifenthaler, 2011; Novak, 1998).

This study extends previous cognitive models research in the geosciences (Kastens et al., 2009; McNeal et al., 2008; Rappaport, 2009). Cognitive science researchers view conceptual and cognitive models as two different types of models. Specifically, according to Norman (1983), "conceptual models are devised as tools for the understanding or teaching of physical systems," and "mental [i.e., cognitive] models are what people really have in their heads and what guides their use of things." This study utilizes Norman's definitions of mental or cognitive models. Furthermore, the method used by Norman to discuss cognitive models is adopted and modified as described in Arthurs (2011). It provides syntax for clearly framing the distinctions in cognitive models of the same concept held by experts, defined by the general scientific community, defined by teachers for the purposes of level-appropriate instruction, and held by novices. It also recognizes that the researcher is privy to only the parts of an individual's cognitive models that they self-report in verbal, written, or drawn form. Such self-reported data possess known limitations (Stone et al., 2000). These limitations include, for example, an individual (i) might think one way and not be aware enough of it to express it or (ii) might be aware enough of his thinking to satisfactorily express it but does not do so for a variety of reasons, including wanting to provide the response they believe is expected or correct (Norman, 1983). Furthermore, conceptualizations are not necessarily stable over time (Libarkin et al., 2003) or coherent relative to other personally held ideas (DeLaughter et al., 1998; Mark et al., 1999). Despite the known limitations with self-reported data, such data are the mainstay for cognitive models researchers and are collected and analyzed in this study to determine how novices explain a complex Earth phenomenon, hurricane formation.

\section{METHODS}

\section{Methodology}

This study received Institutional Review Board (IRB) approval to conduct human subjects research at the participating institutions. This exploratory study utilized a pragmatism methodology because it is concerned with applications and solutions to problems, uses data collection and analysis approaches that make sense in the research context, and is done with the intention of further research that is informed by the current research (Creswell, 2003). Within this study, elements of both traditional qualitative and quantitative research approaches are utilized. In particular, the questionnaire elicits open-ended responses, which are qualitative data useful for studying participants' ideas about the world around them (Kvale \& Brinkmann, 2009). The sample size $(n=326)$ is larger than that obtained for traditional qualitative studies; however, our purpose was to explore the range of ideas and different representations (Gaskell, 2000) to a level of detail that is enriched by the larger sample size. Our focus was on sample adequacy, not sample 
size. According to Bowen (2008), sample adequacy relates to demonstrating saturation of categories by which depth and breadth of information is achieved. This is aligned with achieving what Glaser and Strauss (1967) called maximum variation, through constant comparative analysis (which we describe in the Data Analysis section). The large sample size also lends itself to limited statistical chi-square analyses of some of the quantified qualitative data. We utilized a short open-ended questionnaire because previous research (Arthurs, 2011) that compared the utility of using four different approaches for studying student cognitive models showed that open-ended questionnaires are of greatest utility with respect to the quality of responses, data richness for revealing students' conceptions or cognitive models, and the larger number of participants needed to identify a broad range of ideas and saturate the emergent categories. A qualitative and mixed-methods researcher unaffiliated with the study provided a peer review of our methods and found them appropriate for the study.

\section{Locating the Study and the Researchers}

This study was conducted at two Ph.D. granting, research extensive universities in two geographically distinct states in the USA, Georgia and Nebraska. Georgia is located on the eastern coast of the USA and abuts the Atlantic Ocean, whereas Nebraska is located near the center of the country and is entirely landlocked. Georgia is much more prone to hurricane landfall than Nebraska. Compared to Nebraska, Georgia is also in much closer proximity to other states that are also directly impacted by hurricanes (Figure 1). Both universities had a total student population of $\sim 20,000$ during the period of data collection. The authors are researcher-participants (Feig, 2011) because they were the instructors for three of the five courses from which participants for this study were recruited.

\section{Participants}

Purposive sampling is often used in education research (Lopez et al. 1997; Seidler, 1974; Smith, 1983; Zelditch, 1962), and we used purposive sampling to study undergraduate novices' explanations of hurricane formation. One of the authors taught at both institutions and administered the questionnaire while at each institution. Qualitative studies used to identify diverse views related to a specific topic typically include five to 25 participants (Kvale \& Brinkmann, 2009). This study, however, is unique because it includes 326 participants. They were surveyed in five introductory college-level geosciences courses: Environmental Geology A ( $\mathrm{n}=168$, which is $72 \%$ of total enrollment), Environmental Geology B ( $n=67$, which is $87 \%$ of total enrollment), Weather and Climate ( $n=46$, which is $57 \%$ of total enrollment), Physical Geology A ( $\mathrm{n}=34$, which is $60 \%$ of total enrollment), and Physical Geology B ( $\mathrm{n}=11$, which is $8 \%$ of total enrollment). These lower-division courses were selected because they historically enroll students who are novices to geoscience seeking to satisfy their general education core requirements for science and/or meet the requirements for geoscience majors at the participating institutions.

Drawing correlations with specific demographic data is not part of the research questions for this study. For this reason, demographic data were not collected from all courses; however, such data were collected from the Environmental Geology A course and the Environmental Geology B course (Table 1). In these courses, the majority of study participants were freshmen and sophomores; were not science, technology, engineering, and mathematics (STEM) majors; and were in-state residents. Based on historical enrollment patterns for the other three courses, the demographics are similar to the first two courses insofar as the students are mainly freshmen and sophomores, in-state residents, and non-STEM majors. These five courses, therefore, were reasonable places to recruit participants for this study about novices' alternate conceptions about hurricane formation.

\section{Data Collection}

Participants responded to a short, paper-based, open-ended questionnaire that simply asks:

How do hurricanes form? (1) Explain, in your own words, how a hurricane forms. (2) Draw and label a diagram to help illustrate your answer.

The first part of the questionnaire elicits a textual response and the second part elicits a diagrammatic response. The main question was designed with two additional parts in order obtain two different but complimentary ways of 
communicating the participants' ideas so that the researchers could more fully understand participants' ideas about hurricane formation. All participant responses were written in English.

Prior to using this open-ended questionnaire for the purposes of this study, the questionnaire was part of a pilot study in 2010. The pilot study was conducted in Georgia with 252 undergraduate students enrolled in an introductory-level college geoscience course to evaluate the validity of the questionnaire. In particular, the pilot study examined whether the questionnaire was interpreted in the intended manner and that the elicited responses would be rich enough and clear enough for the researchers to obtain an understanding of students' alternate conceptions about how hurricanes form. The results of the pilot study indicated that the questionnaire was interpreted in the manner intended and yielded the type of data-rich responses that would be useful for studying how novices understand hurricane formation, thus providing evidence of the questionnaire's validity.

Table 1. Participant demographics.

\begin{tabular}{|c|c|c|}
\hline Demographic & $\begin{array}{c}\text { GA }_{\text {EnvGeo }} \% \\
(n=168)\end{array}$ & $\begin{array}{c}\mathbf{N E}_{\text {EnvGeo }} \% \\
(n=67)\end{array}$ \\
\hline Male & 64 & 66 \\
\hline Female & 36 & 34 \\
\hline Freshman & 36 & 39 \\
\hline Sophomore & 44 & 24 \\
\hline Junior & 11 & 15 \\
\hline Senior & 9 & 15 \\
\hline Standing unknown & 41 & 7 \\
\hline Geoscience major & 0 & 1 \\
\hline STEM major & 22 & 22 \\
\hline Non-STEM major & 78 & 75 \\
\hline Major unknown & 0 & 3 \\
\hline Lived in state for some time & 100 & 100 \\
\hline
\end{tabular}

Note:. $\mathrm{GA}=$ Georgia. $\mathrm{NE}=$ Nebraska. Demographic information for participants recruited from the two Environmental Geology courses (one in GA, USA, and one in NE, USA).

In all five previously described courses from which participants were recruited, the questionnaire was administered in class between the fifth and seventh week of a 15-week semester. Students in all five courses did not receive any instruction about how hurricanes form before the questionnaire was administered. Only one of the courses, the Weather and Climate course, discussed atmospheric processes at all prior to the time that the questionnaire was administered but, again, they did not receive explicit instruction about how hurricanes form.

For the present study, participants in Georgia were surveyed in 2011 and participants in Nebraska were surveyed in 2012. In the two aforementioned Environmental Geology courses, the questionnaire was administered as an in-class activity worth two points towards class participation. In the Weather and Climate course and the two Physical Geology courses, the questionnaire was administered anonymously without course credit or other incentive.

A potential sampling bias exists in the collected data because (i) only students present in class on the day that the questionnaire was administered could choose to participate and (ii) students self-volunteered to participate. Despite the potential sampling bias, the questions this study aims to answer require that the participants be novices to geoscience and this requirement is deemed met for all participants because of their enrollment in introductory-level college geoscience courses. Note, it is beyond the scope of the present study to conduct evaluations of each participant's knowledge and skills in the geosciences domain, and enrollment in an introductory-level college geoscience course is used as a proxy for participants' novice-like levels of mastery in the geosciences domain.

To prepare the collected paper-based questionnaires for analysis, individual responses were made anonymous, assigned an arbitrary alpha-numeric ID, and transcribed verbatim in Excel by one of the co-authors. The sketches were digitized and saved electronically. In the transcribed responses, sketches were described with key words for referencing purposes (e.g., "sketch of collision" and "sketch of low pressure"), but printed scans of the participants" original sketches were used for the diagrammatic analysis. 


\section{Data Analysis}

\section{Constant Comparative Analyses}

After the raw data was transcribed and digitized, the textual content analyses (Sapsford, 1999) and diagrammatic analysis (Gobert, 2000; Sibley, 2005) were conducted using constant comparative analyses to discover categories and themes in the collected data about the participants' conceptions of hurricane formation. The selected method of constant comparative analysis is an adaptation of the one developed by Strauss and Corbin (1990).

First, one of the co-authors defined the unit of analysis and the levels of granularity to conduct the analyses that would effectively serve as the basis for coding and subsequent analysis to answer the research questions. Holsti (1969) stresses the importance of correctly defining the unit of analysis as an essential first-step decision to systematically analyzing qualitative data. The unit of analysis defined for this study are not "text chunks" (Simons, 1993) but "thought units" or "units of meaning" (Buber et al., 2004). Each thought unit represents one communicated idea, irrespective of whether it is expressed in a single word, sign (e.g., a plus sign), or punctuation mark (e.g., a question mark); a verb-object sequence; a complete sentence; or an extended narrative.

The same co-author defined two levels of granularity to conduct the constant comparative analyses. The first is at the level of the whole response. In the whole-response constant comparative analysis, each response is analyzed to identify the single thought unit about the initiating or dominant process behind hurricane formation in each participant's explanation. The second level of analysis identifies additional thought units about hurricanes and their formation that might appear in each participant's explanation. The results of this parsed-response constant comparative analysis may yield zero to several thought units related to hurricanes in general beyond the one identified during the whole-response analysis.

The same co-author carefully read all responses for the constant comparative analyses to develop two schemes of emergent categories and themes, one for the whole-response analysis and one for the parsed-response analysis. As prior research into novices' and laymen's conceptions of hurricanes has not been conducted at this deep level, no existing a priori categories were used. After the two schemes were developed the other co-author reviewed them for content, clarity, and organization; this review contributed to the scheme's validity and trustworthiness.

\section{Development and Application of Coding Rubrics}

The two schemes described above were then translated into coding rubrics that were then iteratively revised by the two authors through their application to the participant responses, discussion of discovered ambiguities in the rubrics, and discussion of discrepant coding between both authors. The final version of the full whole-response coding rubric is shown in Table 2 and an abbreviated version in Table 3. The final version of the full parsed-response coding rubric is in Table 4 . Tables 2 and 4 both list the categories that emerged during the initial stage of the constant comparative analyses. They also show how these categories are aggregated into broader major themes.

In Table 2, the whole-response Themes A-G are listed in order from the least expert-like ideas to the most expert-like ideas. While Themes A-G have at least some semblance of scientific relevance to hurricane formation, Theme $\mathrm{H}$ does not and is therefore listed last in Tables 2 and 3. In Table 4, the parsed-response categories associated with each theme are listed from the most to the least expert-like ideas. The emergent themes into which the emergent categories are aggregated are expressed as questions; note that these are not questions in the questionnaire. These questions are themes that represent implicit questions about hurricanes and their formation that participants addressed in their openended responses.

Using the whole-response coding rubric, each participant's whole response can be assigned to one and only one category based on the initiating or dominant process discussed in the participant's explanations of how hurricanes form. Each major theme is assigned at least one representative sketch and one representative statement from participants' responses for content clarification about the theme. Responses are coded based on what initiates hurricane formation. If no initiating process is indicated, then the dominant hurricane-related process described in the 
participant's response is coded. Two coders (the authors) independently applied the whole-response rubric to all 326 questionnaires with initial intercoder reliability (Kurasaki, 2000; Yeaton \& Worton, 1993) of 93\%. Differences in coding were resolved through discussion and led to $100 \%$ agreement in the final codes assigned to each response.

Using the parsed-response coding rubric, a single whole response can be parsed into separate textual and diagrammatic units. In this way, unlike the coding conducted with the whole-response rubric, a single whole response can be assigned more than one code with this rubric. One co-author was the coder who applied the parsed-response rubric to all 326 questionnaires. An Excel spreadsheet was developed to record the codes. The coding reliability was checked and re-checked; the coder applied the parsed-response coding rubric to the collected data four times, with one-week to six-month intervals between each application. During each of these applications, only minor adjustments were made, if any, providing evidence of high reliability. This check-coding supported the relative consistency of the coder's judgement over time (Krefting, 1991; Miles \& Huberman, 1994).

\section{Comparison of Novice Explanations against Expert Explanation}

Although there remain yet-to-be answered scientific questions about specific details of hurricanes (e.g., Wuebbles $e t$ al., 2014), there does exist agreement in the scientific community about how hurricanes form.

Table 2, part 1 of 2. Whole-response coding rubric with supporting examples of participant statements.

\begin{tabular}{|c|c|c|c|}
\hline \multicolumn{2}{|c|}{ Emergent Theme } & & Emergent Category \\
\hline \multirow{2}{*}{$\begin{array}{l}\text { Alpha } \\
\text { Code }\end{array}$} & \multirow{2}{*}{ Hurricanes form due to } & \multirow{2}{*}{$\begin{array}{c}\text { Numeric } \\
\text { Code }\end{array}$} & Initiating or Dominant Process for Hurricane Formation \\
\hline & & & Representative example of participant statement \\
\hline \multirow{8}{*}{ A } & \multirow{8}{*}{$\begin{array}{l}\text { Atmospheric bodies } \\
\text { colliding, meeting, or } \\
\text { mixing. }\end{array}$} & \multirow{2}{*}{1} & Two atmospheric bodies collide. \\
\hline & & & Low pressure system collides with a tropical storm. \\
\hline & & \multirow{2}{*}{2} & Hot air and cold air collide. \\
\hline & & & Hot and cold winds meet. \\
\hline & & \multirow{2}{*}{3} & Dry air and moist air collide. \\
\hline & & & Very dry air collides with moist air. \\
\hline & & \multirow{2}{*}{4} & High pressure and low pressure collide. \\
\hline & & & High and low pressure systems mix. \\
\hline \multirow{2}{*}{ B } & \multirow{2}{*}{$\begin{array}{l}\text { Air/Wind and water } \\
\text { meeting. }\end{array}$} & \multirow{2}{*}{5} & Air/ Wind and water meet. \\
\hline & & & Warm air and cold water meet creating a rotating storm system. \\
\hline \multirow{4}{*}{$\mathrm{C}$} & \multirow{4}{*}{$\begin{array}{l}\text { Water currents meeting } \\
\text { AND/OR water moving } \\
\text { in circles. }\end{array}$} & \multirow{2}{*}{6} & Hot and cold bodies of water mix. \\
\hline & & & Hot and cold water mixing rapidly in a circular motion. \\
\hline & & \multirow{2}{*}{7} & Water currents meet and/or Water moves in circles. \\
\hline & & & Hot and cold water currents meet and force water upward. \\
\hline \multirow{4}{*}{$\mathrm{D}$} & \multirow{4}{*}{$\begin{array}{l}\text { Air, wind, or storms } \\
\text { move; hurricanes are } \\
\text { storms. }\end{array}$} & \multirow{2}{*}{8} & Forms from (strong) winds or moving air. \\
\hline & & & Air starts to circulate. \\
\hline & & \multirow{2}{*}{9} & Forms from storms; are storms. \\
\hline & & & Caused by storms or wind and rain or bad weather. \\
\hline \multirow{11}{*}{$\mathrm{E}$} & \multirow{11}{*}{$\begin{array}{l}\text { Differences in pressure, } \\
\text { temperature, and/or air } \\
\text { flow exist. }\end{array}$} & \multirow{2}{*}{10} & Pressure/ Temperature changes. \\
\hline & & & Forms when temperature or pressures changes. \\
\hline & & \multirow{2}{*}{11} & Pressure/ Temperature gradients exist. \\
\hline & & & Forms due to gradients of temperature and/or pressure. \\
\hline & & \multirow{2}{*}{12} & Pressure increases. \\
\hline & & & Forms when air pressure increases. \\
\hline & & 13 & $\begin{array}{l}\text { There is movement from high pressure area to low pressure area. } \\
\text { Air moves from area of high pressure to low pressure. }\end{array}$ \\
\hline & & \multirow[b]{2}{*}{14} & Warm air rises and cold air descends. \\
\hline & & & Hot air rises and cold air drops. \\
\hline & & \multirow[b]{2}{*}{15} & A more detailed role of pressure and temperature. \\
\hline & & & $\begin{array}{l}\text { Heated air rises and forms clouds, low pressure area forms, wind } \\
\text { flows from high to low pressure, and heat from water sustains } \\
\text { hurricane. }\end{array}$ \\
\hline
\end{tabular}

Note. Themes and categories emerged from the whole-response constant comparative analysis. 
For this study, Gardiner's (2009) explanation and illustration of hurricane formation were used as the expert-defined standard against which we contrasted the novice responses. This explanation does not include finer-grained details known by experts on hurricane genesis, but it addresses the mastery level of understanding participating instructors agreed was appropriate for introductory-level college geoscience courses. Below, we describe Gardiner's explanation of hurricane formation:

A hurricane (or tropical cyclone) forms when a cluster of storms organizes in the atmosphere and intensifies to form a tropical depression (wind speed: $38 \mathrm{mi} / \mathrm{h}$ or $61 \mathrm{~km} / \mathrm{h}$ ), intensifies further to form a tropical storm (wind speed: $39-73 \mathrm{mi} / \mathrm{h}$ or $63-117 \mathrm{~km} / \mathrm{h}$ ), and then further intensifies to form a hurricane (wind speed: $\geq 74$ $\mathrm{mi} / \mathrm{h}$ or $\geq 119 \mathrm{~km} / \mathrm{h})$. Warm ocean water $\left(\geq 80^{\circ} \mathrm{F}\right.$ or $\left.\geq 26.6^{\circ} \mathrm{C}\right)$ provides energy that sustains a hurricane. Ocean surface water evaporates, warm moisture-laden air rises into the atmosphere, and an area of low pressure forms. As the warm air rises, it cools, condenses, and forms clouds. Light prevailing winds outside the hurricane steer it and let it grow. Relatively cooler air outside the hurricane is drawn into its central low pressure area; the air is warmed and collects evaporated water; and it rises, cools, and condenses, thus continuing the process. A hurricane's rotation is due to the Coriolis effect, which is caused by Earth's rotation. A hurricane weakens and dissipates when it moves over cooler ocean water or land.

Table 2, part 2 of 2. Whole-response coding rubric with supporting examples of participant statements.

\begin{tabular}{|c|c|c|c|}
\hline \multicolumn{2}{|r|}{ Emergent Theme } & & Emergent Category \\
\hline \multirow{2}{*}{ Code } & \multirow{2}{*}{ Hurricanes form due to } & \multirow{2}{*}{ Code } & Initiating or Dominant Process for Hurricane Formation \\
\hline & & & Representative example of participant statement \\
\hline \multirow{8}{*}{$\mathrm{F}$} & \multirow{8}{*}{$\begin{array}{l}\text { A low pressure area forming; } \\
\text { hurricanes form around low } \\
\text { pressure area. }\end{array}$} & \multirow{2}{*}{16} & Forms when air spirals into a low pressure area. \\
\hline & & & Winds converge around a low pressure system in the ocean. \\
\hline & & \multirow{2}{*}{17} & $\begin{array}{l}\text { Forms when air spirals into a low pressure area due to PGF (pressure } \\
\text { gradient force) }\end{array}$ \\
\hline & & & $\begin{array}{l}\text { Forms when a low pressure system develops and due to the PGF wind } \\
\text { goes to the low. }\end{array}$ \\
\hline & & \multirow{2}{*}{18} & Low pressure area forms (over ocean water). \\
\hline & & & A low pressure area dips into the tropics. \\
\hline & & \multirow[b]{2}{*}{19} & Low pressure area forms over warm water and under rising air. \\
\hline & & & $\begin{array}{l}\text { Warm air rises from just above warm ocean and low pressure area forms } \\
\text { under rising air. }\end{array}$ \\
\hline \multirow{8}{*}{ G } & \multirow{8}{*}{$\begin{array}{l}\text { Warm air, moist air, water } \\
\text { evaporation, or uplift of water } \\
\text { forms clouds/storms. }\end{array}$} & \multirow{2}{*}{20} & Warm air rises and forms winds/clouds/storm. \\
\hline & & & Warm air rises and forms clouds, storms, or hurricane. \\
\hline & & \multirow{2}{*}{21} & Warm moist ocean air forms clouds/storm. \\
\hline & & & Warm moisture-filled air forms clouds, cyclone, storms, or hurricane. \\
\hline & & \multirow{2}{*}{22} & Warm ocean water evaporates and condenses to form clouds/storm. \\
\hline & & & Warm water vaporizes and "feeds" the storm. \\
\hline & & \multirow[b]{2}{*}{23} & Warm ocean water/vapor is sucked up and forms clouds. \\
\hline & & & $\begin{array}{l}\text { Low pressure system sucks warm water vapor from ocean, forms clouds, } \\
\text { begins to rotate, increases in strength, and decreases in pressure. }\end{array}$ \\
\hline \multirow[b]{2}{*}{$\mathrm{H}$} & \multirow{2}{*}{ Plate tectonics } & \multirow{2}{*}{24} & Plate tectonics. \\
\hline & & & Hurricane forms by certain movement of tectonic plates. \\
\hline
\end{tabular}

Note. Themes and categories emerged from the whole-response constant comparative analysis. 
Table 3. Abbreviated whole-response coding rubric and results.

\begin{tabular}{|c|c|c|c|c|}
\hline $\begin{array}{l}\text { Alpha } \\
\text { Code }\end{array}$ & Theme: Hurricanes form due to ... & GA $\%(n=168)$ & NE \% (n=158) & $\begin{array}{l}\text { Total \% } \\
(\mathrm{n}=\mathbf{3 2 6})\end{array}$ \\
\hline A & atmospheric bodies come into contact with one another. & 37 & 34 & 35 \\
\hline $\mathrm{B}$ & air/wind and water meeting. & 19 & 9 & 14 \\
\hline $\mathrm{C}$ & water currents meeting and/or water moving in circles. & 3 & 3 & 3 \\
\hline $\mathrm{D}$ & air, wind, or storm moving. & 20 & 23 & 22 \\
\hline E & differences in pressure, temperature, and/or air flow. & 5 & 12 & 9 \\
\hline $\mathrm{F}$ & $\begin{array}{l}\text { a low pressure area forming, or hurricanes form around } \\
\text { low pressure area. }\end{array}$ & 8 & 8 & 8 \\
\hline G & $\begin{array}{l}\text { warm air, moist air, water evaporation, or uplift of water } \\
\text { forming clouds/storms. }\end{array}$ & 6 & 7 & 6 \\
\hline $\mathrm{H}$ & tectonic plates moving. & 1 & 4 & 3 \\
\hline
\end{tabular}

Note. $\mathrm{GA}=$ Georgia. $\mathrm{NE}=$ Nebraska.

Table 4. Parsed-response coding rubric and results.

\begin{tabular}{|c|c|c|c|c|}
\hline Emergent Theme & Emergent Category & $\begin{array}{c}\text { GA \% } \\
(n=168)\end{array}$ & $\begin{array}{c}\mathrm{NE} \% \\
(\mathrm{n}=158)\end{array}$ & $\begin{array}{l}\text { Total \% } \\
(\mathrm{n}=326)\end{array}$ \\
\hline \multirow{5}{*}{$\begin{array}{l}\text { A. Where do hurricanes } \\
\text { form? }\end{array}$} & 1. Over warm/tropical ocean water & 21 & 17 & 19 \\
\hline & 2. Over ocean/sea/off land/off coast & 39 & 44 & 41 \\
\hline & 3. Over warm water & 7 & 4 & 5 \\
\hline & 4. Over water & 15 & 15 & 15 \\
\hline & 5. Over land & 5 & 5 & 5 \\
\hline \multirow{5}{*}{$\begin{array}{l}\text { B. What Earth system } \\
\text { components are involved in } \\
\text { hurricane formation? }\end{array}$} & 1. Atmosphere and ocean & 25 & 16 & 21 \\
\hline & 2. Ocean & 3 & 3 & 3 \\
\hline & 3. Atmosphere & 67 & 77 & 72 \\
\hline & 4. Land & 1 & 1 & 1 \\
\hline & 5. Tectonic plates & 2 & 5 & 3 \\
\hline \multirow{5}{*}{$\begin{array}{l}\text { C. What causes a hurricane } \\
\text { to rotate? }\end{array}$} & 1. Coriolis effect & 1 & 3 & 2 \\
\hline & 2. Moving air/wind & 4 & 3 & 3 \\
\hline & 3. Bodies of air collide with each other & 16 & 17 & 16 \\
\hline & 4. Moving ocean water & 2 & $<1$ & 1 \\
\hline & 5. Tectonic plates collide with each other & 0 & $<1$ & $<1$ \\
\hline \multirow{5}{*}{$\begin{array}{l}\text { D. What is the direction of } \\
\text { movement of air and water } \\
\text { in a hurricane? }\end{array}$} & 1. Vertical movement of water (as gas) & 9 & 6 & 8 \\
\hline & 2. Vertical movement of air (as gas) & 12 & 8 & 10 \\
\hline & 3. Lateral movement of air (as gas) & 73 & 77 & 75 \\
\hline & 4. Vertical movement. of water (as liquid) & 7 & 3 & 5 \\
\hline & 5. Lateral movement of water (as liquid) & 8 & 9 & 8 \\
\hline \multirow{4}{*}{$\begin{array}{l}\text { E. What causes a hurricane } \\
\text { to intensify? }\end{array}$} & 1. Obtains heat from warm ocean water & 8 & 8 & 8 \\
\hline & 2. Obtains heat (unspecified source) & 3 & 2 & 2 \\
\hline & 3-4. Picks up water as liquid or gas & 5 & 5 & 5 \\
\hline & 5. Moves over the ocean & 8 & 14 & 10 \\
\hline \multirow{2}{*}{$\begin{array}{l}\text { F. What determines a } \\
\text { hurricane's path? }\end{array}$} & 1. Wind moves storm toward land & 2 & 2 & 2 \\
\hline & $\begin{array}{l}\text { 2. It follows path of ocean current, } \\
\text { ocean currents push it to land }\end{array}$ & 3 & 1 & 2 \\
\hline \multirow{5}{*}{$\begin{array}{l}\text { G. How is ocean water } \\
\text { affected during hurricane } \\
\text { formation? }\end{array}$} & $\begin{array}{l}\text { 1. Evaporation of ocean water; } \\
\text { latent heat released }\end{array}$ & 5 & 9 & 1 \\
\hline & $\begin{array}{l}\text { 2. Something picks up moisture, humidity, or water } \\
\text { vapor }\end{array}$ & 1 & 7 & 4 \\
\hline & 3. Large wave(s) of water / like tsunami & 5 & 8 & 6 \\
\hline & 4. A whirlwind/cyclone/tornado of water & 7 & 5 & 6 \\
\hline & 5. Something in atmosphere picks up water & 14 & 8 & 11 \\
\hline
\end{tabular}

Note. Themes and categories emerged from the parsed-response constant comparative analysis.

$\mathrm{GA}=$ Georgia. $\mathrm{NE}=$ Nebraska 


\section{RESULTS}

\section{Variation in Novices' Alternate Conceptions}

A wide variety of novices' alternate conceptions about hurricane formation were identified. The final application of the whole-response rubric in coding the 326 questionnaires yielded 24 categories and eight themes of novice conceptions about the initiating or dominant process that drives hurricane formation (Table 2). In explaining this complex scientific phenomenon, how hurricanes form, the novices to geoscience who were surveyed communicated a variety of conceptions in terms of types (i.e., the emergent themes) and degrees of specificity and accuracy (i.e., the emergent categories).

The three most frequently occurring themes listed in order from the most frequent to the least frequent are: Theme $\mathrm{A}$ (35\%), Theme D (22\%), and Theme B (14\%). Theme A (35\%) represents the alternate conception or cognitive model of hurricanes forming due to atmospheric bodies (e.g., clouds or fronts) coming into contact with one another. Furthermore, there are two main ways that the surveyed novices to geoscience conceptualize the interaction between these two atmospheric bodies, either gradually or rapidly. Gradual contact of these bodies is exemplified in the use of language in their explanations such as "mix," "meet," and "come together." These explanations are accompanied by representative sketches such as those shown in Figure 2. In contrast, the conception that atmospheric bodies come into rapid and even violent contact with one another is communicated in their explanations with the use of language such as "collide" and sketches that suggest that the two bodies crash into one another (Figure 2). Whether the contact is gradual or rapid, the expert explanation used as the basis for comparison does not describe hurricanes forming due to two atmospheric bodies colliding with one another.

Theme D (22\%) represents the alternate conception or cognitive model of hurricanes forming due to air, wind, or storms moving and its representative sketches are like those often seen on newspaper, televised, and online weather reports (Figure 2). These explanations do represent a level of accuracy about hurricane formation but only in the most general of terms; indeed, a hurricane is a storm with moving air/wind. These explanations do not, however, explain what causes a hurricane to actually form.

Theme B (14\%) represents the alternate conception or cognitive model of hurricanes forming due to "air" or "wind" meeting with "water" and is characterized by representative statements such as "Warm air and cold water meet creating a rotating storm system," "A tornado [strong wind] touches down on water," and "Strong winds and water unite in rapid motion." These kinds of statements are accompanied by representative sketches such as those in Figure 2. These explanations convey the conception that what is responsible for hurricane formation is wind blowing down on large bodies of water. It is not wind blowing down onto water but wind blowing into an area of low pressure over a warm ocean surface that is key.

The two least frequently occurring themes of conceptions for how hurricanes form are Theme $\mathrm{C}(3 \%)$ and Theme $\mathrm{H}$ (3\%). Theme $\mathrm{C}$ represents the alternate conception or cognitive model of hurricanes forming due to water currents meeting one another and/or water moving in circles, and Theme $\mathrm{H}$ represents the alternate conception or cognitive model of hurricanes forming due moving tectonic plates. Based on only the participant responses provided, it is unclear exactly how these participants connected tectonic plates with hurricane formation. One possible explanation is that these participants think that moving tectonic plates cause the ocean water to move in an upward swirling way to form a hurricane, as reflected in Theme G. Follow-up interviews with the participants would help test this explanation and clarify students' ideas for the researchers, but such follow-up interviews were beyond the scope of the present study.

The remaining three themes are Theme $\mathrm{E}(9 \%)$, Theme $\mathrm{F}(8 \%)$, and Theme $\mathrm{G}(6 \%)$, and they are discussed here in the order from the most frequently to the least frequently occurring. Theme $\mathrm{E}$ reflects the general conception or cognitive model that hurricanes form due to differences in pressure, temperature, and/or air flow. The categories and associated representative participant statements for Theme $\mathrm{E}$ are listed from the vaguest to the least vague. A statement that illustrates the vaguest category is "[Hurricanes form] when temperature or pressure changes," whereas a statement that illustrates the least vague category is "[Hurricanes form when] heated air rises and forms clouds, low pressure area forms, wind flows from high to low pressure, and heat from water sustains hurricane." 
Theme $\mathrm{F}(8 \%)$ reflects the alternate conception or cognitive model that hurricanes form because a low pressure region forms or that hurricanes form around a low pressure region. It is comprised of four categories (Table 2). As with Theme E, these categories also lend themselves to being listed from the most to the least vague. The vaguest category in this theme is illustrated by a representative participant statement, "[Hurricanes form] when air spirals into a low pressure system in the ocean." At the same time, the least vague category is illustrated by another representative participant statement, "[Hurricanes form when] warm air rises from just above warm ocean and low pressure area forms under rising air."

Theme G (6\%) reflects the alternate conception or cognitive model that hurricanes form due to warm and/or moist air, water evaporation, or the uplift of liquid water which forms clouds/storms. The most expert-like conceptions held among the surveyed novices appeared as thought units that are classified under Theme G. In particular, numeric category codes 20-22 (Table 2) include mention of key factors involved in hurricane formation such as warm ocean water, evaporation, rising air, etc. Although most of the responses under Theme G tend toward being more expertlike, responses assigned code 23 reveal clear conceptions involving the rising up of liquid water into the atmosphere. The drawings associated with Theme G (Figure 2) aid in further communicating the range of conceptions. For example, they include water vapor rising up (Figure $2 \mathrm{w}$ and $2 \mathrm{x}$ ), liquid water spiraling into a rotating column of water as it is sucked up (Figure 2y), ocean water being sucked up (Figure 2z), and large waves rising up (Figure 2aa).

Figure 2. Summary of representative sketches associated with each of the whole-response themes. These sketches are reproductions or tracings of key diagrammatic components that appeared in participants' drawings. These components were selected during the whole-response constant comparative analysis because they are directly connected to participants' ideas about the initiating or dominant process behind hurricane formation.

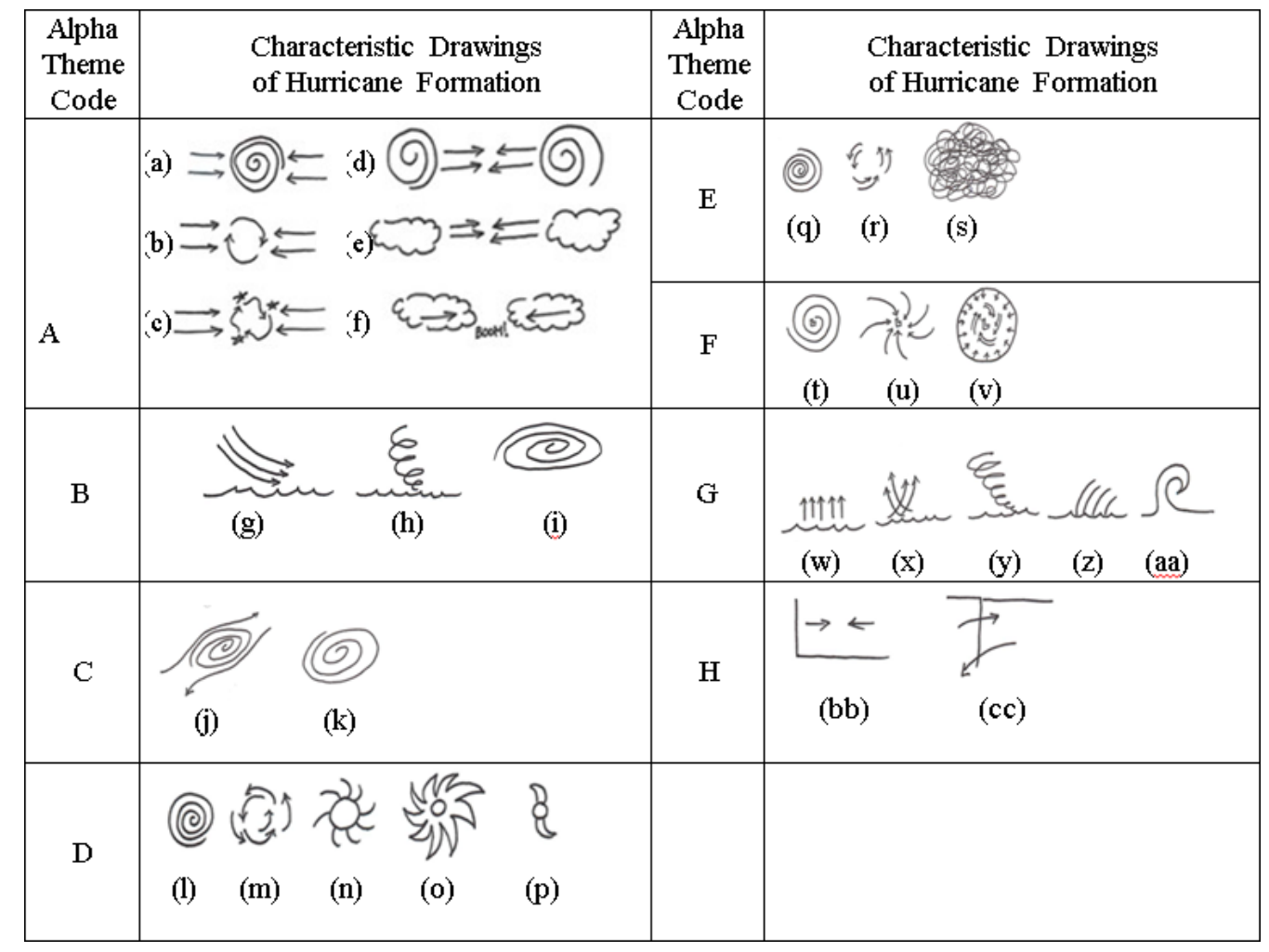

\section{Distribution of Novices' Alternate Conceptions}

The results of the whole-response coding were quantified and plotted in order to illustrate the frequency with which different conceptions are observed (Figure 3). Herein, these are referred to as distribution profiles of alternate conceptions. Figure 3a illustrates the distribution of the themes of novices' conceptions about hurricane formation in 
the total sample population, whereas Figure $3 b$ illustrates the distribution profiles in terms of the subpopulations from Georgia $(n=168)$ and from Nebraska $(n=158)$. Figure $3 \mathrm{~b}$ shows that all themes of novice conceptions about hurricane formation are shared to some extent between the two subpopulations. Conceptions that were held to a similar extent include water currents meet (Theme C), hurricanes form around a low pressure area (Theme F), and warm moist air is uplifted (Theme G). The most frequent conception for both subpopulations is that two atmospheric bodies contact each other (Theme A), and this type of conception is documented elsewhere (Westgate, 1978). Figure 3b also shows there are notable variations in the extent to which the two subpopulations conceive of hurricane formation. For example, more than twice as many Georgian participants attributed hurricane formation to interactions between wind and water (i.e., Theme B) than did Nebraskan participants. Meanwhile, more than twice as many Nebraskan participants generally stated that hurricanes form due to differences in pressure, temperature, or airflow (i.e., Theme C) than did Georgian participants.

The Georgian and Nebraskan participant populations are large enough that the overall distribution profiles of alternate conceptions for each can be statistically compared. The nominal (versus ratio or interval) scale associated with the quantified qualitative data and having only a single theme assigned to each participant (using the whole-response rubric) means that a chi-square test of independence is appropriate for determining whether the distribution profiles of alternate conceptions held by Georgian and Nebraskan participants are statistically different. The results of this analysis are $\chi^{2}(7, N=326)=14.27, p<0.025$. They suggest that there is a statistically significant difference between the two populations.

Figure 3. Distribution of profiles of alternate conceptions that emerged during the whole-response constant comparative analysis. The purpose of the whole-response constant comparative analyses is to identify the initiating or dominant process behind hurricane formation. Figure $3 \mathrm{a}$ shows the distribution profile for the total population of study participants. Figure $3 \mathrm{~b}$ shows the distribution profiles for participants in Georgia (GA) and Nebraska (NE). A=Atmospheric bodies come into contact with one another. $\mathrm{B}=\mathrm{Air} /$ wind and water meet. $\mathrm{C}=$ Water currents meet and/or water moves in circles. $\mathrm{D}=\mathrm{Air}$, wind, or storms move. $\mathrm{E}=\mathrm{Differences}$ in pressure, temperature, and/or air flow. $\mathrm{F}=\mathrm{A}$ low pressure area forms or hurricanes form around a low pressure area. $\mathrm{G}=\mathrm{W}$ arm air, moist air, water evaporation, or uplift of water forms clouds/storms. H=Plate tectonics.

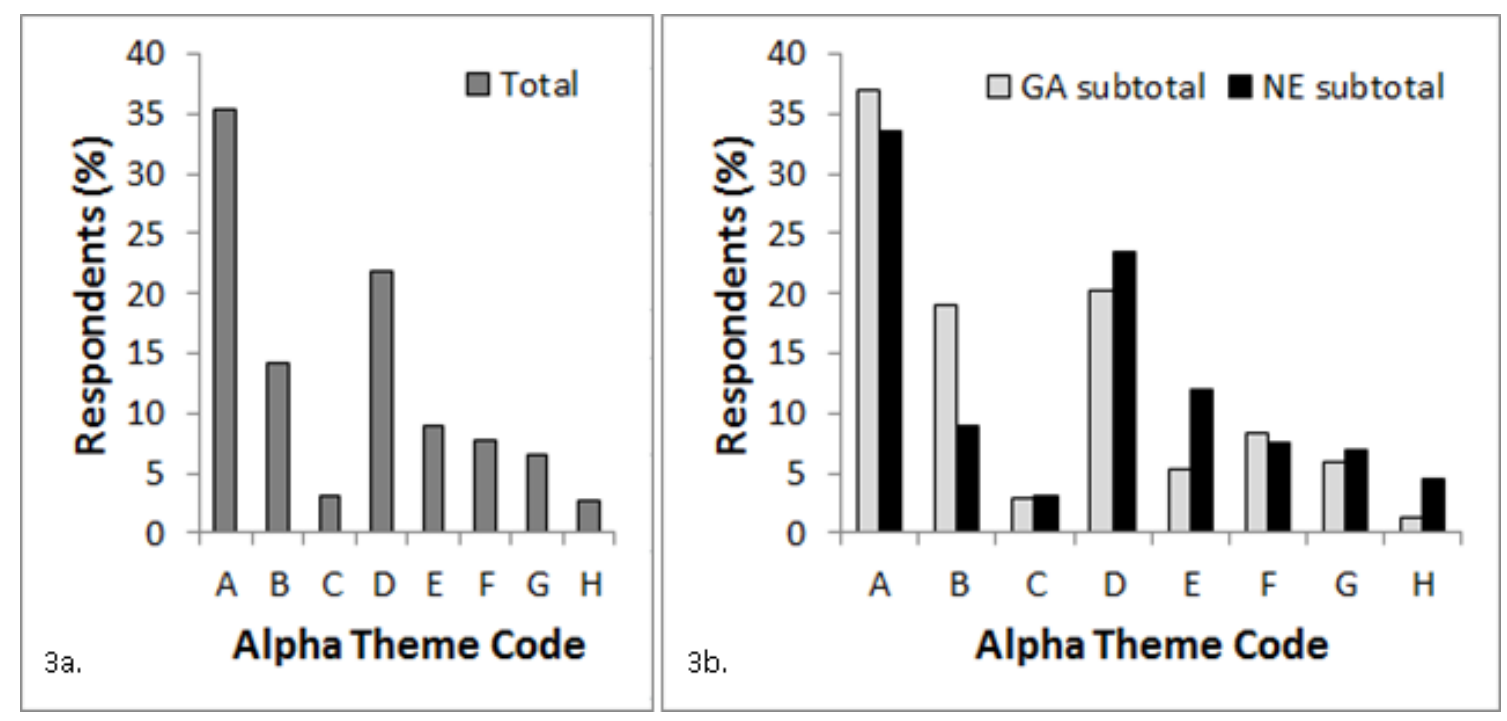

It is, however, worth noting that students in the Weather and Climate course in Nebraska had not yet learned about hurricanes up to the time that the questionnaire was administered in their class. They did, nevertheless, already learn about some atmospheric concepts, such as pressure gradients and temperature gradients in particular, which could influence their responses. In fact, six references to these concepts were made in the collected responses and all six came from participants in this course. To test whether student responses from this course might skew the Nebraskan subset of data, a chi-square test of independence was used to analyze the data without the responses from only that course. The results of this analysis are $\chi^{2}(7, N=280)=13.66, p<0.05$. 
The combined results of both these chi-square tests of independence support one another in suggesting that (i) there is a statistically significant difference between the observed Georgian and Nebraskan distribution profiles of alternate conceptions, and (ii) the difference is not due to responses collected from the Weather and Climate course.

Furthermore, the collected data show that students in this course also held alternate conceptions that fit into Themes $\mathrm{A}, \mathrm{B}, \mathrm{D}, \mathrm{E}, \mathrm{F}$, and $\mathrm{G}$. Themes $\mathrm{C}$ and $\mathrm{H}$ were the least frequently occurring in the total population surveyed and it is therefore not alarming that these conceptions did not occur in this course.

Despite the survey being administered in this course about a third of the way through the semester, the instruction that students received about weather and climate up to that point did not significantly alter the variety of conceptions about hurricane formation when compared to students in other courses. Thus, it is appropriate to retain these students in the total sample for the purposes of exploring novice-like conceptions.

\section{Contrasting Emergent Novice Conceptions with Pre-Defined Expert Conception}

The expert geoscientist explanation for hurricane formation used a standard against which to contrast novices' explanations is described in the Methods section. The final application of the parsed-response rubric (Table 4) to code the 326 participants' questionnaires yielded 37 emergent categories. Note, it is possible for a single whole response to either include or not include one or more thought units classifiable under these categories. As such, the frequency counts associated with each category do not add up to the total number of participants. These categories were aggregated into themes. Seven of these themes are reported here and represented as questions that relate to hurricane formation. These themes, expressed as questions, are not items on the questionnaire; instead, they represent implicit questions that participants addressed in their open-ended responses and, as such, they are emergent themes. These themes, their categories, and occurrence frequency are shown in Table 4.

The first theme, Theme A, is: Where do hurricanes form? The majority of participants (80\%) indicated that hurricanes form over water of some kind. Incorrectly, $5 \%$ specified that they form over land or with tectonic plates. Correctly, $19 \%$ specified that they form over warm oceans.

The second theme, Theme B, is: What Earth system components are involved in hurricane formation? The majority of participants $(72 \%, \mathrm{n}=232)$ indicated that hurricanes are strictly atmospheric phenomena, $3 \%$ indicated that they are strictly oceanic phenomena, and $3 \%$ indicated they are the product of tectonic plate movement. Only $21 \%$ of participants correctly indicated that hurricanes form due to interactions between the ocean and the atmosphere.

The third theme, Theme C, is: What causes hurricane rotation? About $16 \%$ of participants indicated that the collision when two atmospheric bodies meet causes hurricanes to rotate, and $1 \%$ indicated that the movement of ocean water causes the hurricane to rotate. A small minority (2\%) correctly stated the Coriolis effect is involved in the rotation.

The fourth theme, Theme D, is: What is the direction of movement of air and/or water? Of the 326 respondents, $75 \%$ $(\mathrm{n}=244)$ included mention of lateral air movement in their text, concept sketch, or both. Only $10 \%$ included mention of vertical air movement. Vertical movement of air is also an integral part of hurricane formation, as warm moist air rises off the ocean surface; however, only a minority of respondents mentioned vertical air movement. Table 4 captures one level of data analysis granularity classified under Theme $\mathrm{D}$, but there is a finer-grained level of analysis and it is discussed here. Among participants, $8 \%$ indicated lateral movement of liquid water, $8 \%$ indicated vertical movement of water as vapor/gas, $5 \%$ indicated vertical movement of liquid water from the ocean into the atmosphere, and $15 \%$ drew concept sketches with spiraling columns of air/water rising off the ocean surface. An example of a representative participant statement that exemplifies this particular thought unit is:

"A hurricane forms when very strong winds cross each other and form a wind cyclone over the ocean. This sucks water from the ocean and as more water is collected into the warm air the more powerful the hurricane becomes." 
The fifth theme, Theme E, is: What causes a hurricane to intensify? Eighty-five participants (25\%) addressed this theme. Of them, 27 participants (8\%) accurately identified a hurricane's location over warm water as the cause of hurricane intensification, with approximately the same percentages from Georgia and Nebraska. Other reasons provided for why hurricanes intensify included their movement over the ocean, their need for heat, and their picking up water/moisture.

The sixth theme, Theme $\mathrm{F}$, is: What determines the hurricane's path? A smaller percentage of participants ( $4 \%, \mathrm{n}=14)$ addressed this theme. Of them, seven participants (2\%) correctly attributed wind as the mechanism that drives hurricanes toward land, while another seven identified ocean currents as the driving factor.

The seventh theme, Theme G, is: How is ocean water affected during hurricane formation? Approximately $33 \%$ of participants addressed this theme. Six percent of the participants described the formation of a "whirlwind," "cyclone," or "tornado" of water; $6 \%$ indicated that large waves of water or tsunami form; $11 \%$ stated that something picks up ocean water; $11 \%$ indicated that something picks up "moisture," "humidity," or "water vapor"; and 1\% indicated that ocean water evaporates. The most expert-like of the participants' associated with this theme is that "ocean water evaporates."

\section{DISCUSSION}

\section{Variation and Distribution of Alternate Conceptions}

All major themes described in the whole-response rubric are present in both the Georgian and Nebraskan subpopulations. Although these two subpopulations of novices to geoscience have alternate conceptions in common, the frequencies with which they appear are statistically significantly different, as shown in the chi-squared tests of independence previously described. Because these subpopulations are similar demographically in the ways needed for this study (i.e., novices to geoscience), the observed difference in their distribution profiles of alternate conceptions (Figure 3b) appears to be related to their geographic locations and other possible location-related variables. That is, the observed difference may be due to the participants' experiences living in a state that is historically more directly affected by hurricane landfalls (i.e., Georgia) and its neighboring states versus living in a state that is far from any area in the USA where hurricanes make landfall in the USA (i.e., Nebraska). However, testing this explanation is beyond the scope of the present study and presents a possible avenue for future research.

Although further research is needed to explain the observed difference in these two subpopulations' distribution profiles of alternate conceptions, the work of others such as Lakoff (1987) and Atwater (2012) demonstrate that the place where one lives informs the development of their conceptions. The data presented in this article suggests that some conceptions about hurricane formation transcend location, whereas others may be influenced by each subpopulation's prior knowledge and experiences living in the two locations sampled for this study.

\section{Theoretical Models to Characterize Cognitive Models}

Conceptual change (Vosniadou, 1994) is often discussed in terms of progressing along a spectrum from novice to expert ways of thinking (Chi et al., 1981; Johnson et al., 1981; Larkin, 1985). Building on the notion that expertise develops in a linear progression from a novice state to an expert state and utilizing a constant comparative approach to analyze and interpret participants' explanations of hurricane formation, two original theoretical models were generated to synthesize the empirically ascertained cognitive models or alternate conceptions. Each theoretical model coherently synthesizes, knits together, and visually represents the novice alternate conceptions or cognitive models identified in this study relative to one another and relative to the expert conception described in the Methods section. To do so, the first model plots the location of emergent themes identified using the whole-response rubric along a theoretical novice-to-expert spectrum, and the second model plots the location of emergent themes identified using the parsed-response rubric. 


\section{Model 1}

The first model, the whole-response model (Figure 4), is not comprised of a single linear novice-to-expert spectrum. Instead, it has two spectra that are connected to each other at their expert ends. One spectrum primarily plots conceptions that deal with physical movement of "observable" components in the Earth system. The second spectrum plots conceptions that deal with "unobservable" physical or chemical process. The closer a conceptual theme is plotted to the expert ends of the spectra, the more expert-like it is; and the closer it is plotted to the opposite end of each spectrum, the more novice-like it is. The conception of hurricane formation being due to moving air (Theme D) is plotted on both spectra because moving air is not necessarily observable but evidence of moving air is observable (e.g., trees swaying in the wind).

Figure 4. Model 1, the whole-response model. The purpose of the whole-response constant comparative analyses is to identify the initiating or dominant process behind hurricane formation. Each downward-descending arrow in Model 1 represents a spectrum of novice-like to expert-like conceptions. The darker the color along the spectrum, the more expert-like the conception is. Both arrows move toward and converge at the expert conception.

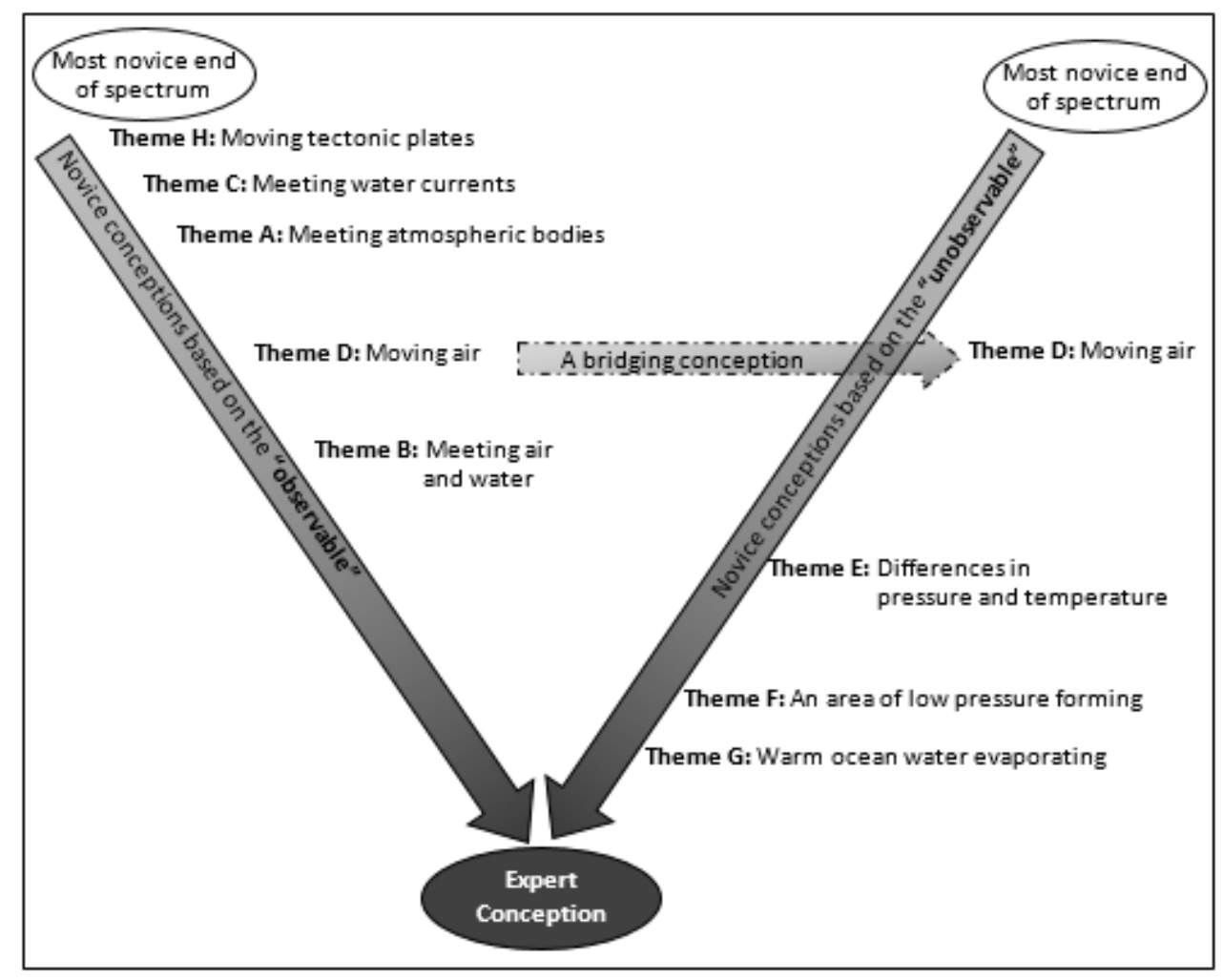

This theoretical model has implications from the perspective of teaching novices to geoscience about hurricane formation. First, it highlights the fact that novices employ overly simplistic heuristics (Kahneman, 2011) to explain a complex scientific phenomenon, thus suggesting that instructional strategies to help novices develop more scientifically accurate explanations - whether it be to explain the formation of hurricanes or other complex phenomena - need to be developed, tested, and implemented in classroom teaching. Second, because the conception that moving air is responsible for hurricane formation is related to both spectra, a potentially useful starting point for teaching novices about hurricane formation is discussing with them what air is and what causes it to move. Because students have prior knowledge about moving air in their everyday life experiences (e.g., seeing trees swaying in the wind or seeing sand blowing around) this "observable" heuristic could be capitalized on in order to build novices' understanding of the "unobservable" scientific first principles that underlie hurricane formation and move them along the second spectrum towards more expert-like thinking. 


\section{Model 2}

The second model, the parsed-response model (Figure 5), is also not characterized by a single novice-to-expert spectrum. Instead, it is comprised of seven axes that intersect at the center of five concentric circles, forming a noviceto-expert web. This novice-to-expert web is an innovation from this research. Each axis relates to one of the emergent themes and contributes to the level of detail described in an individual's explanation of hurricane formation. Each concentric circle relates to the level of accuracy relevant to a specific theme and evident in the same individual's explanation. The more themes that are addressed, the more detailed the explanation is; and the closer that the statements about each theme are plotted to the center of the orb web, the more accurate the explanation is. The more detailed and accurate an explanation is, the more expert-like it is.

Figure 5. Model 2, the parsed-response model. The purpose of the parsed-response constant comparative analyses is to identify information that participants included in their responses beyond the initiating or dominant process behind hurricane formation. Model 2 is characterized by seven axes that intersect at the center of five concentric circles, forming a web. Each axis relates to one of the emergent themes and contributes to the level of detail described in an individual's explanation of hurricane formation. Each concentric circle relates to the level of accuracy relevant to a specific theme and apparent in the same individual's explanation. The more themes that are addressed, the more detailed the explanation is; and the closer the statements about each theme are plotted to the center of the web, the more expert-like that statement is. [] indicate ideas that were not seen in the sampled population's responses.

\begin{tabular}{|c|c|c|c|c|}
\hline \multirow{2}{*}{\multicolumn{5}{|c|}{ I Theme Evel of Accuracy }} \\
\hline & & & & \\
\hline & & & 4 & 5 \\
\hline A. Where & \begin{tabular}{|l|}
$\begin{array}{l}\text { Over warm } \\
\text { ocean water }\end{array}$ \\
\end{tabular} & Over ocean & On/over water & On/over land \\
\hline B. Components & $\begin{array}{l}\text { Atmosphere \& } \\
\text { ocean }\end{array}$ & Ocean & Land & Tectonic plates \\
\hline C. Sustained rotation & Coriolis effect & Moving air & $\begin{array}{l}\begin{array}{l}\text { Moving ocean } \\
\text { water }\end{array} \\
\end{array}$ & $\begin{array}{l}\text { Colliding } \\
\text { tectonic plates }\end{array}$ \\
\hline $\begin{array}{l}\text { D. Direction of } \\
\text { movement of what }\end{array}$ & $\begin{array}{l}\text { Vertical, warm } \\
\text { water (as gas) }\end{array}$ & Vertical, air & $\begin{array}{l}\text { Vertical, water } \\
\text { (as gas) }\end{array}$ & $\begin{array}{l}\text { Lateral, water } \\
\text { (as liquid) }\end{array}$ \\
\hline E. Energy source & Warm ocean & $\begin{array}{l}\text { Unspecified } \\
\text { heat source }\end{array}$ & $\begin{array}{l}\text { Water } \\
\text { (as liquid) }\end{array}$ & $\begin{array}{l}\text { Motion over } \\
\text { ocean }\end{array}$ \\
\hline F. Path control & $\begin{array}{l}\text { [vertical wind } \\
\text { shear] }\end{array}$ & [beta drift] & $\begin{array}{l}\text { [interaction with } \\
\text { land] }\end{array}$ & Ocean currents \\
\hline G. Ocean water & $\begin{array}{l}\text { Ocean water } \\
\text { evaporates }\end{array}$ & $\begin{array}{l}\text { Water (gas) is } \\
\text { picked up }\end{array}$ & $\begin{array}{l}\text { Water tornado } \\
\text { forms in ocean }\end{array}$ & $\begin{array}{l}\text { Water (liquid) is } \\
\text { picked up }\end{array}$ \\
\hline
\end{tabular}

Application of this model is illustrated using two complete explanations from the collected questionnaires (Figure 6). The corresponding novice-to-expert webs are illustrated in Figure 6. 
Figure 6. Two examples of novice-to-expert. The first example shows that the student does not provide a very detailed description but that is provided are more expert-like in terms of accuracy. The second example shows that the student has twice as much detail as the first example, has the same level of accuracy for Theme A and Theme B, and has fairly novice-like ideas about Theme E and Theme G.

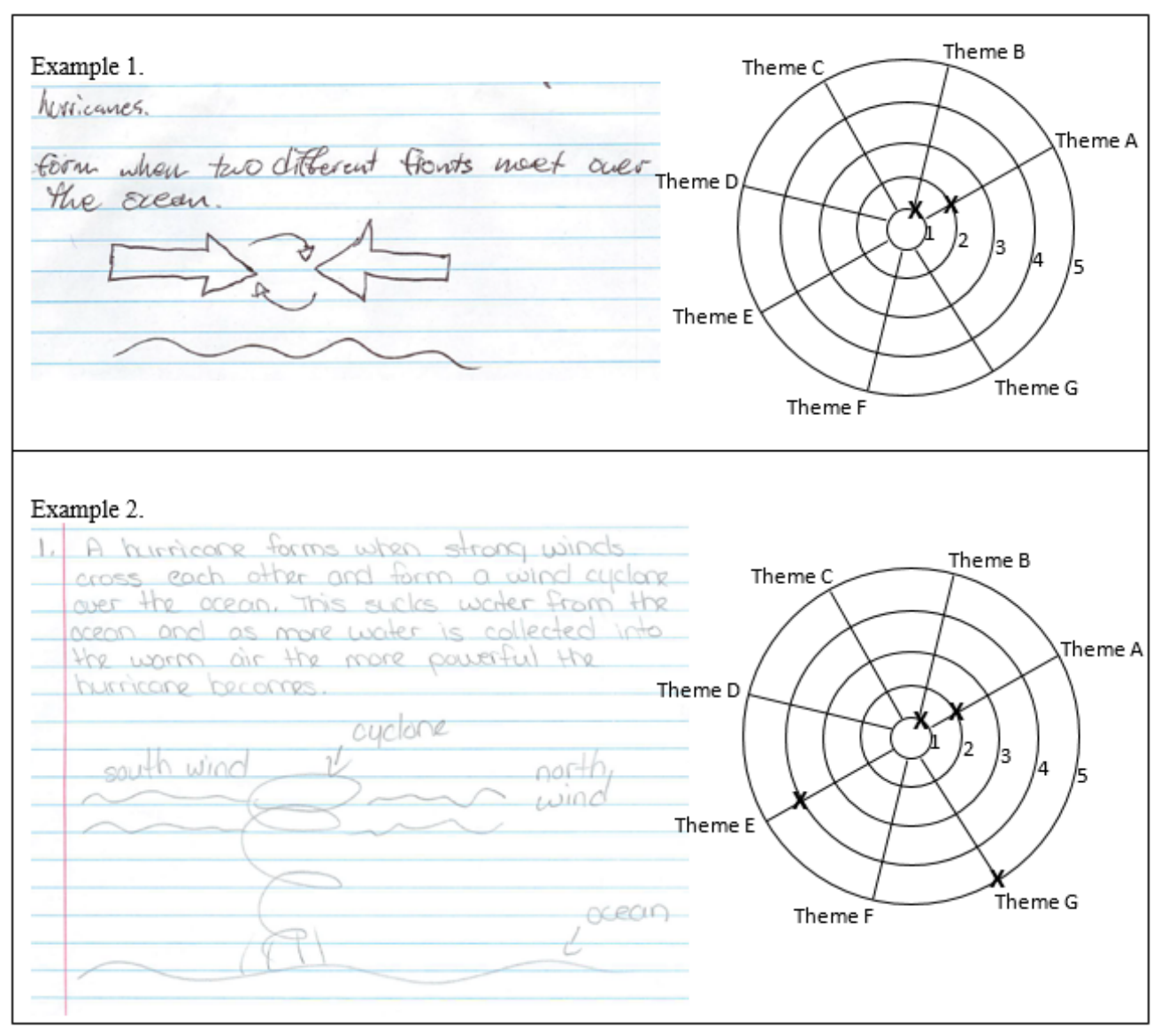

Plotting individuals' explanations on novice-to-expert webs can serve as a useful tool that can be used by teachers and researchers to visually characterize and quickly summarize where a student is in their developmental path towards greater expertise. The novice-to-expert web can be completed by a teacher or researcher at different time points relative to instruction as a way to illustrate conceptual change that might occur from one point in time to another. For demonstration purposes, Figure 7 represents the product of a thought experiment using the novice-to-expert web. It is a completed novice-to-expert web that plots fictitious but plausible pre- and post-instruction explanations from a hypothetical student. With it, one can quickly see that the hypothetical student became more expert-like in her explanation during the hypothetical instructional period. An inspection of the axes for Theme $\mathrm{C}$ and Theme $\mathrm{F}$ shows that there is no change after instruction. In the case of Theme $\mathrm{C}$, the student failed to address this aspect of hurricane formation both before and after instruction, hence the absence of data markers on this axis. Novice-to-expert webs can be developed for and are transferable to other in-depth studies of alternate conceptions, conceptual change, and the development of expertise. They also have the potential to be used by practicing (geo)science teachers to provide students feedback regarding their conceptual development. 


\section{Explanations of Earth Phenomena and Scientific Literacy}

Skills that are characteristic of experts include, for example, the ability to call on and appropriately apply knowledge to new and different contexts outside the original context in which they were learned in order to explain and solve problems (Chi et al., 1981; Johnson et al., 1981; Larkin, 1985; Libarkin \& Kurdziel, 2006). Geoscientists invoke such knowledge in the form of scientific first principles to describe and hypothesize about myriad Earth phenomena. First principles that can be invoked to explain how hurricanes form include, for example: (i) Heat is the transfer of energy, (ii) Changes in temperature contribute to changes in phase, (iii) Differences in temperature contribute to differences in buoyancy, and (iv) Differences in gradient control flow.

Figure 7. Demonstration of novice-to-expert web as a tool for plotting conceptual change. This figure demonstrates how the novice-to-expert web can be used to plot a student's ideas about hurricanes before and after instruction. The data plotted are fictitious and purely for demonstration purposes. The figure illustrates a hypothetical scenario of individual conceptual change where the hypothetical student holds more expert-like conceptions about hurricane formation after the hypothetical learning period.

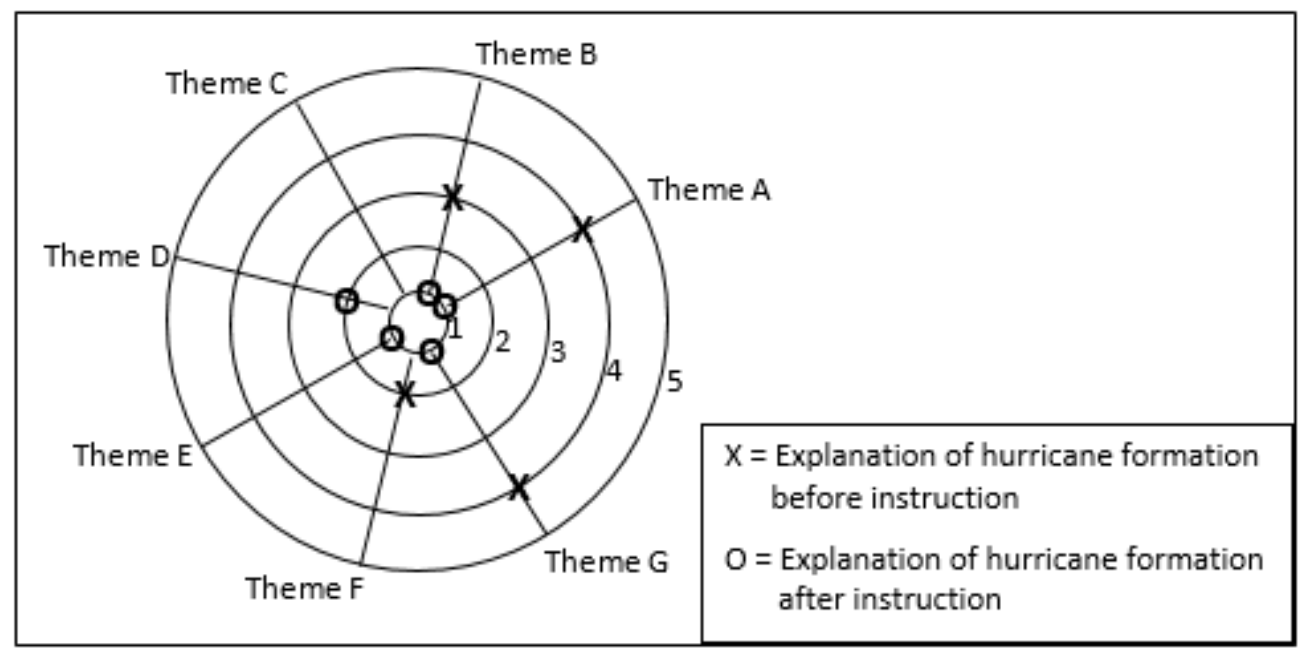

These are scientific first principles that are well matched with learning goals outlined in Project 2061's Benchmarks for Science Literacy (American Association for the Advancement of Science, 1993); the benchmarks are gradeappropriate learning goals that educators can use to design core curriculum that will aid students in the USA to achieve science literacy goals outlined in Science for All Americans (Rutherford \& Ahlgren, 1990). In particular, the first principle of interest listed above (i.e., heat is the transfer of energy) is well aligned with two learning goals that students are expected to achieve by the end of eighth grade: (i) "Energy can be transferred from one system to another (or from a system to its environment) in different ways: 1) thermally, when a warmer object is in contact with a cooler ..." and (ii) “... Thermal energy can also be transferred by means of currents in air, water, or other fluids." The second principle of interest listed above (i.e., changes in temperature contribute to changes in phase) corresponds well with a learning goal that students are expected to achieve by the end of eighth grade: "Water evaporates from the surface of the earth, rises, and cools, condenses into rain or snow, and falls again to the surface." The third principle of interest listed above (i.e., differences in temperature contribute to differences in buoyancy) is in accord with a learning goal that students are expected to achieve by the end of fifth grade: "Heating and cooling can cause changes in the properties of materials, but not all materials respond the same way to being heated and cooled." The fourth principle of interest listed above (i.e., differences in gradient control direction of flow) is best matched with another learning goal that students are expected to achieve by the end of eighth grade:

Transfer of thermal energy between the atmosphere and the land or oceans produces temperature gradients in the atmosphere and the oceans. Regions at different temperatures rise or sink or mix, resulting in winds and ocean currents. These winds and ocean currents, which are also affected by the earth's rotation and the shape of the land, carry thermal energy from warm to cool areas. 
Although the scientific first principles that we identified as useful for applying to explanations of hurricane formation are associated with learning goals that college students in the USA should achieve in middle- and high-school, very few of this study's participants drew on them to explain how hurricanes form. Table 5 lists statements taken from participants' responses that illustrate how each first principle can be invoked in order to explain how hurricanes form. Nevertheless, analysis of the collected data shows that novices to geoscience overwhelmingly do not invoke first principles to explain Earth processes. Possible reasons why these first principles might not be invoked by novices to geoscience include: (i) a lack of familiarity with them, (ii) a lack of proficiency in applying them, and (iii) a preference for the easy use of access heuristics over more effortful thinking (Kahneman, 2011).

The fundamental scientific first principles discussed above directly relate to the idea of "abstract scientific knowledge" that appears in the PISA 2006 Science's rubric for internationally assessing 15-year old students' proficiency in explaining scientific phenomena (Bybee et al., 2009). PISA results for all students tested in all of the participating nations in the OECD show that only $\sim 10 \%$ of students demonstrated the highest levels of proficiency in explaining scientific phenomena (Bybee et al., 2009). This study's finding that the vast majority of college students recruited for this study did not utilize scientific first principles is consistent with the PISA results that show students around the world generally have very low proficiency in explaining scientific phenomena. The PISA Science 2006 science literacy score for 15-year old students in the USA is below the OECD average (Bybee et al., 2009), and this study's findings support this low PISA score for the USA and shows that this deficiency is propagated to and retained at the college level.

Table 5. Scientific first principles useful for explaining hurricane formation.

\begin{tabular}{l|l}
\hline \multicolumn{1}{c}{ First Principle } & Representative Example of Participant Application of First Principle \\
\hline \multirow{2}{*}{ 1. Heat is the transfer of energy. } & Warm ocean water provides energy for the hurricane. \\
\cline { 2 - 2 } $\begin{array}{l}\text { 2. Changes in temperature contribute to changes } \\
\text { in phase change. }\end{array}$ & Warm ocean water leads to evaporation of ocean water. \\
\cline { 2 - 2 } $\begin{array}{l}\text { 3. Differences in temperature contribute to } \\
\text { differences in buoyancy. }\end{array}$ & Cool moist air condenses, changes from gas to liquid. \\
\hline $\begin{array}{l}\text { 4. Differences in gradient control direction of } \\
\text { flow. }\end{array}$ & Cool air descends. \\
\hline
\end{tabular}

Note. The representative examples of participants' application of the first principles are included in the actual student language used in their responses.

\section{SUMMARY}

Using a pragmatism methodology (Creswell, 2003), this exploratory research addressed the broad problem that the geoscience education community has of not understanding the alternate conceptions that students bring with them to the classroom setting (National Research Council, 2012), which may help or hinder their continued learning (Bransford, 1999). The purpose of this study was to more fully understand the conceptions about hurricane formation that novices bring to the classroom for the express intention of future research to develop and test items for formative and summative assessments (Rivet \& Kastens, 2012). In this way, the identified alternate conceptions may also be integrated into classroom instruction in such a way as to move geoscience students from more novice-like to more expert-like ways of thinking about and explaining scientific phenomena; that is, to develop appropriate scaffolding (Chi et al., 1994; Reiser, 2004) that could also be informed by, for example, the theoretical models presented herein.

The data collected here suggest a wide variation of alternate conceptions through careful, in-depth, and timeconsuming analysis of qualitative data collected from 326 college students at two different state universities in the USA to discover how they explain a specific scientific phenomenon, how hurricanes form. All of the major themes of novice conceptions that emerged in the whole-response coding process are present among the novice explanations of hurricane formation collected in both subpopulations, in Georgia $(\mathrm{n}=168)$ and in Nebraska $(\mathrm{n}=158)$. Nevertheless, the subpopulations' distribution profiles of alternate conceptions are statistically different.

PISA Science 2006 used the ability to explain scientific phenomena as one of several features in their definition of scientific literacy. The present examination of novices' explanations of how hurricanes form reveals that novices 
generally do not invoke scientific first principles to explain this Earth phenomenon, even though students in the USA are expected to learn these first principles in their middle- and high-school science courses.

Although studies of geoscience conceptions to date do identify misconceptions for a given concept, such as the water cycle (Ben-zvi-Asarf \& Orion, 2005; Dickerson \& Dawkins, 2004; Reinfried, 2006; Schwartz et al., 2011), this is the first study using a pragmatism methodology (Creswell, 2003) that systematically identifies and characterizes novice alternate conceptions by examining all data collected from a very large sample population (versus a small subset of a larger data set) for a targeted in-depth analysis of a single concept (hurricane formation). This type of study is unprecedented in misconceptions research, mainly because of the heavy time commitment needed to systematically analyze qualitative data of such size. Moreover, this study utilized the accepted practice of constant comparative analysis to generate two original empirically-supported theoretical models, which build on the (geo)science education community's existing notion of conceptual change occurring along a single spectrum from novice-like ways of thinking to expert-like ways of thinking. In doing so, this study offers alternative ways to view the development of expertise. Taken together, the findings of this study provide insights that can help inform Earth science educators on how students' alternate conceptions about hurricane formation could be used to scaffold learning. Furthermore, the novice-to-expert webs developed to characterize the extent to which an individual's explanation of hurricane formation is like the expert conception, in terms of detail and accuracy, represents a model that has the potential for transferability to other misconceptions research. That is, modeling expertise in terms of detail and accuracy can be done with other data-rich qualitative studies about alternate conceptions.

This study's findings lead to the following recommendations:

- Implement learner-centered strategies that allow students to resolve scientific inaccuracies in their prior knowledge, build on what they know in appropriately scaffolded ways, and practice applying scientific first principles in their explanations of scientific phenomena.

- Tailor existing general interactive engagement strategies such as interactive demonstrations (Crouch et al., 2004), peer instruction (Crouch \& Mazur, 2001), and classroom assessment techniques (Angelo \& Cross, 1993) to the learning goals related to course concepts.

- Use existing knowledge of novices' alternate conceptions to develop (i) well-scaffolded course curricula and materials and (ii) valid and reliable instruments such as concept inventories.

- Continue to deepen the geoscience education community's knowledge of novices' alternate conceptions through continued research in this area.

- Pursue research that examines the potential regional and other location-influenced factors that can shape individuals' alternate conceptions or cognitive models.

The findings of this study form the basis of future work that can lead to (i) the development of research-based items for use in diagnostic, formative, and summative assessments; (ii) the development of a research-based multiple-choice survey that can be more widely distributed and more quickly analyzed; and (iii) further investigations to characterize potentially regionally-informed alternate conceptions.

\section{AUTHOR AUTOBIOGRAPHIES}

Leilani A. Arthurs, Ph.D. is a member of the Department of Earth \& Atmospheric Sciences and the Center for Science, Math, \& Computer Education at the University of Nebraska-Lincoln. She has a PhD in Civil Engineering and Geological Sciences and four certificates in pedagogy from the University of Notre Dame. She worked with Nobel Prize winner, Dr. Carl Wieman for three years to transform college science teaching and conduct science education research. She is a recipient of NSF funding that supports (i) the recruitment and retention of students in the geosciences and (ii) college STEM faculty adoption of research-based instructional strategies.

Matthew S. Van Den Broeke, Ph.D. is a member of the Department of Earth and Atmospheric Sciences at the University of Nebraska-Lincoln. He has a Ph.D. in Meteorology from the University of Oklahoma, and specializes in radar applications to severe weather, including hurricanes and tornadic thunderstorms. He also studies undergraduate perceptions of severe weather risk. He is a recipient of NSF funding supporting (i) radar study of biological targets, 
(ii) atmospheric measurements using unmanned aircraft systems, and (iii) effects of changing Great Plains land cover on regional precipitation patterns and severe weather environments.

\section{REFERENCES}

American Association for the Advancement of Science. (1993). Benchmarks for science literacy. New York: Oxford University Press.

Angelo, T. A., \& Cross, K. P. (1993). Classroom assessment techniques: A handbook for faculty. Ann Arbor, MI: National Center for Research to Improve Postsecondary Teaching and Learning.

Arthurs, L. (2011). What college students think: Student alternate conceptions and their cognitive models of geoscience concepts. In A. D. Feig, \& A. Stokes, (Eds.), Qualitative inquiry in geoscience education research: Geological Society of America special paper 474 (135-152). Boulder, CO: Geological Society of America.

Atwater, M. M. (2012). Significant science education research on multicultural science education, equity, and social justice. Journal of Research in Science Teaching, 49(1), 01-05.

Ben-zvi-Assarf, O., \& Orion, N. (2005). A study of junior high students' perceptions of the water cycle. Journal of Geoscience Education, 53(4), 366-373.

Bereiter, C., \& Scardamalia, M. (1986). Educational relevance of the study of expertise. Interchange, 17(2), 10-19.

Bowen, G. (2008). Naturalistic inquiry and the saturation concept: a research note. Qualitative Research 8(1): 137-142.

Bransford, J., Brown, A. L., Cocking, R. R., \& National Research Council (U.S.). (1999). How people learn: Brain, mind, experience, and school. Washington, D.C: National Academy Press.

Buber, R., Gadner, J., \& Richards, L. (2004). Applying qualitative methods to marketing management research. Houndmills, Basingstoke, Hampshire: Palgrave Macmillan.

Bybee, R. McCrae, B., \& Laurie, R. (2009). PISA 2006: An assessment of scientific literacy. Journal of Research in Science Teaching, 46(8), 865-883.

Capps, D. K., McAllister, M., \& Boone, W. J. (2013). Alternative conceptions concerning the Earth's interior exhibited by Honduran Students. Journal of Geoscience Education, 61, 231-239.

Carley, S., Chen, R., Halversen, C., Jacobson, M., Livingston, C., Matsumoto G., Payne, D., Paytan, A., Schoedinger, S., Strang, C., Tran, L.U., Tuddenham, P., Whitley, L., \& Wilson. S. (2013). Ocean Literacy: The Essential Principles and Fundamental Concepts of Ocean Sciences for Learners of All Ages Version 2. Available at http://www.coexploration.org/oceanliteracy/documents/OceanLitChart.pdf (accessed 28 December 2014).

Chang, H.-Y. \& Linn, M. C. (2013). Scaffolding learning from molecular visualizations. Journal of Research in Science Teaching, 50(7), 858-886.

Chi, M. T. H., Feltovich, P. J., \& Glaser, R. (1981). Categorization and representation of physics knowledge by experts and novices. Cognitive Science, 5, 121-152.

Chi, M. T. H., Slotta, J. D., \& De Leeuw, N. (1994). From things to processes: A theory of conceptual change for learning science concepts. Learning and Instruction, 4(1), 27-43.

Clement, J. (1993). Using bridging analogies and anchoring intuitions to deal with students' preconceptions in physics. Journal of Research in Science Teaching, 30(10), 1241-1257.

Creswell, J. W. (2003). Qualitative, quantitative, and mixed methods approaches. Los Angeles: Sage.

Crouch, C. H., \& Mazur, E. (2001). Peer instruction: Ten years of experience and results. American Journal of Physics, 69(9), 970-977.

Crouch, C. H., Fagen, A. P., Callan, J. P., \& Mazur, E. (2004). Classroom demonstrations: Learning tools or entertainment? American Journal of Physics, 72(6), 835-838

Dal, B. (2007). How do we help students build beliefs that allow them to avoid critical learning barriers and develop a deep understanding of geology? Eurasia Journal of Mathematics: Science and Technology Education, 3(4), 251-269.

Dash, N., \& Gladwin, H. (2007). Evacuation decision making and behavioral responses: Individual and household. Natural Hazards Review, 8(3), 69-77.

Delaughter, J. E., Stein, S., Stein. C. A., \& Bain, K. R. (1998). Preconceptions abound among students in an introductory earth science course. EOS, 79(36), 429-136.

Derry, S. (1996). Cognitive schema theory in constructivist debate. Educational Psychologist, 31(3/4), 163-174.

Dickerson, D., \& Dawkins, K. (2004). Eighth grade students' understandings of groundwater. Journal of Geoscience Education, 52(2), 178-181.

Dixon, R. M. W. (1982). Where have all the adjectives gone? Berlin, Germany: Walter de Gmyter.

Dow, K., \& Cutter, S. L. (2000). Public orders and personal opinions: Household strategies for hurricane risk assessment. Environmental Hazards, 2, 143-155.

Driver, R. (1981). Pupils' alternative frameworks in science. European Journal of Science Education, 33, 93-101. 
Feig, A. D. (2011). Methodology and location in the context of qualitative data and theoretical frameworks in geoscience education research. In A. D. Feig, \& A. Stokes (Eds.), Qualitative inquiry in geoscience education research: Geological Society of America special paper 474 (1-110). Boulder, CO: Geological Society of America.

Gardiner, L. (2009). How Hurricanes Form. In National Earth Science Teachers Association website, "Windows to the Universe" Available at http://www.windows2universe.org/earth/Atmosphere/hurricane/formation.html (accessed 26 August 2010).

Gaskell, G. (2000). Individual and group interviewing. In M. Bauer \& G. Gaskell (Eds.), Qualitative Researching with Text, Image and Sound. London: Sage, 38-56.

Glaser, B. \& Strauss A. (1967). The Discovery of Grounded Theory; Strategies for Qualitative Research. Chicago: Aldine.

Gasser-Wingate, M. (2016). Aristotle on Induction and First Principles. Philosopher's Imprint, 16(4), 1-20.

Gobert, J. D. (2000). A typology of causal models for plate tectonics: Inferential power and barriers to understanding. International Journal of Science Education, 22, 937-977.

Helm, H. (1980). Misconceptions in physics amongst South African students. Physics Education, 15, 92-105.

Holsti, O. R. (1969). Content analysis for the social sciences and humanities. Reading: Addison-Wesley.

Ifenthaler, D., Masduki, I., \& Seel, N. M. (2011). The mystery of cognitive structure and how we can detect it: Tracking the development of cognitive structures over time. Instructional Science, 39(1), 41-61.

Internal Revenue Service. (2009). Tax Law Changes to National Disaster Relief, Fact Sheet FS-2009-8. Available at https://www.irs.gov/pub/irs-news/fs-09-08 (accessed 22 November 2013).

Izquierdo-Aymerich, M., \& Aduriz-Bravo, A. (2003). Epistemological foundations of school science. Science and Education, 12, 27-43.

Johnson, P. E., Duran. A. S., Hassebrock, F., Moller, J., Prietula, M., Feltovich, P. J., \& Swanson, D. B. (1981). Expertise and error in diagnostic reasoning. Cognitive Science, 5, 235-283.

Johnson, J., \& Reynolds, S. (2005). Concept sketches: Using student- and instructor-generated, annotated sketches for learning, teaching, and assessment. Journal of Geoscience Education, 53(1), 85-95.

Johnson, R., Snow, J., Abshire, W., Buhr, S., Cullen, H., Denning, S., Holland, M., Manduca, C., Pennington, P., Schoedinger, S., Schultz, P., \& Marshall, J., (2009). Essential Principles and Fundamental Concepts for Atmospheric Science Literacy. Available at http://gcoos.tamu.edu/documents/AtmosphericLiteracy.pdf (accessed 31 July 2010).

Kahneman, D. (2011). Thinking, fast and slow. New York, NY: Farrar, Strauss and Giroux.

Kastens. K. A., Liben, L. S., \& Agmwal, S. (2009). How students and field geologists reason in integrating spatial observations from outcrops to visualize a 3-D geological structure. International Journal of Science Education, 31, 365-393.

Kinchin, I. M., Hay, D. B., \& Adams, A. (2000). How a qualitative approach to concept map analysis can be used to aid learning by illustrating patterns of conceptual development. Educational Research, 42(1), 43-57.

Krefting, L. (1991). Rigor in quantitative research: Assessment of trustworthiness. American Journal of Occupational Therapy, 45, 214-222.

Kurasaki, K. S. (2000). Intercoder reliability for validating conclusions drawn from open-ended interview data. Field Methods, 12(3), 179-194.

Kvale, S., \& Brinkmann, S. (2009). InterViews: Learning the craft of qualitative research interviewing. Los Angeles: Sage Publications.

Lakoff, G. (1987). Women, fire, and dangerous things: What categories reveal about the mind. Chicago, IL: University of Chicago Press.

Larkin, J. H. (1985). Understanding, problem representations, and skill in physics. In S. F. Chipman, J. E. Segal, \& R. Glaser (Eds.), Thinking and learning skills: Research and open questions Volume 2 (141-159). Hillsdale, NJ: Erlbaum.

Lazo, J. K., Waldman, D. M., Morrow, B. H., \& Thacher, J. A. (2010). Household evacuation decision making and the benefits of improved hurricane forecasting: Developing a framework for assessment. Weather and Forecasting, 25, 207-219.

Libarkin, J. C., Beilfuss, M., \& Kurdziel, J. P. (2003). Research methodologies in science education: Mental models and cognition in education. Journal of Geoscience Education, 51(1), 121-126.

Libarkin, J. C., Anderson. S.W., Dahl. J., Beilfull, M., \& Boone, W. (2005). Qualitative analysis of college students' ideas about the Earth: Interviews and open-ended questionnaires. Journal of Geoscience Education, 53(1), 17-26.

Libarkin, J. C., \& Kurdziel. J. P. (2006). Ontology and the teaching of earth system science. Journal of Geoscience Education, 54(3), 108-413.

Lindblom-Ylanne. S., \& Lonka, K. (2001). Students' perceptions of assessment practices in a traditional medical curriculum: Advances in health sciences education. Theory and Practice, 6, 121-140.

Lopez, A., Atran, S., Coley, J. D., Medin, D. L., \& Smith, E. E. (1997). The tree of life: Universal and cultural features of folk biological taxonomies and inductions. Cognitive Psychology, 32, 251-295.

Mark, D. M., Freksa, C., Hirtle, S.C., Lloyd, R., \& Tversky, B. (1999). Cognitive models of geographic space. International Journal of Geographical Information Science, 13(8), 747-774.

McNeal, K. S., Miller, H. R., \& Herbert, B. E. (2008). Developing non-science majors' conceptual models of complex Earth systems in a physical geology course. Journal of Geoscience Education, 56, 201-211.

Miles, M. B., \& Huberman, A. M. (1994). Qualitative data analysis (2nd edition). Thousand Oaks, CA: Sage Publications. 
Morss, R. E., \& Hayden, M. H. (2010). Storm surge and "certain death": Interviews with Texas coastal residents following Hurricane Ike. Weather, Climate, and Society, 2, 174-189.

Mortimer, E. F. (1995). Conceptual change or conceptual profile change? Science and Education, 4, 267-285.

Murphy, P. K. (2007). The eye of the beholder: The interplay of social and cognitive components in change. The Educational Psychologist, 42(1), 41-54.

National Climatic Data Center \& National Oceanic and Atmospheric Administration. (2013). Billion-dollar weather/climate disasters. Available at http://www.ncdc.noaa.gov/billions/ (accessed 4 January 2014)

National Research Council. (2012). Discipline-based education research: Understanding and improving learning in undergraduate science and engineering. Singer, S. R., Nielsen, N. R., \& Schweingruber, H. A. (Eds.). Committee on the Status, Contributions, and Future Directions of Discipline-Based Education Research. Board on Science Education, Division of Behavioral and Social Sciences and Education. Washington, DC: National Academies Press.

Norman. D. A. (1983). Some observations on mental models. In D. Gentner \& A. Stevens (Eds.), Mental models (7-14). Hillsdale, NJ: Lawrence Erlbaum Associates.

Novak. J. D. (1977). A theory of education: Ithaca, NY: Cornell University Press.

Novak, J. D. (1998). Learning, creating, and using knowledge: Concept maps as facilitative tools in schools and corporations. Mahwah, NJ: L. Erlbaum Associates.

Opfer, J. E., Nehm, R. H., \& Ha, M. (2012). Cognitive foundations for science assessment design: Knowing what students know about evolution. Journal of Research in Science Teaching, 49(6), 744-777.

Organization for Economic Co-Operation and Development. (2006). Assessing scientific, reading and mathematical literacy: A framework for PISA 2006. Paris: OECD.

Parham Jr., T. L., Cervato, C., Gallus Jr., W. A., Larsen, M., Hobbs, J., Stelling, P., Greenbowe, T., Gupta, T., Knox, J. A., \& Gill, T. E. (2010). The INVEST volcanic concept survey: Exploring Student Understanding about Volcanoes. Journal of Geoscience Education, 58(3), 177-187.

Rappaport, E. D. (2009). What undergraduates think about clouds and fog. Journal of Geoscience Education, 57(2), $145-151$.

Reiner, M., Slotta, J. D., Chi, M. T. H., \& Resnick, L. B. (2000). Naive physics reasoning: A commitment to substance-based conceptions. Cognition and Instruction, 18(1), 1-34.

Reinfried, S. (2006). Conceptual change in physical geography and environmental sciences through mental model building: The example of groundwater. International Research in Geographical and Environmental Education, 15(1), 41-61.

Reiser, R. J. (2004). Scaffolding complex learning: The mechanisms of structuring and Problematizing student work. The Journal of the Learning Sciences, 13(3), 273-304.

Reusser, L. J., Corbett, L. B., \& Bierman, P. R. (2012). Incorporating concept sketching into teaching undergraduate geomorphology. Journal of Geoscience Education, 60(1), 3-9.

Rivet, A. E., \& Kastens, K. A. (2012). Developing a construct-based assessment to examine students' analogical reasoning around physical models in Earth science. Journal of Research in Science Teaching, 49(6), 713-743.

Rosch, E. (1975). Cognitive reference points. Cognitive Psychology, 7, 532-547.

Rosch. E. (1981). Prototype classification and logical classification: The two systems. In E. Scholnick (Ed.), New trends in cognitive representation: Challenges to Piaget's theory (73-86). Hillsdale, New Jersey: Lawrence Erlbaum Associates.

Rutherford, F. J., \& Ahlgren, A. (1990). Science for all Americans. New York: Oxford University Press.

Sapsford, R. (1999). Survey research. London: Sage.

Schwartz, K. L., Thomas-Hilburn, H., \& Haverland, A. (2011). Grounding Water: Building Conceptual Understanding through Multimodal Assessment. Journal of Geoscience Education, 59, 139-150.

Seidler, J. (1974). On using informants: a technique for collecting quantitative data and controlling measurement error in organization analysis. American Sociological Review, 39, 816-831.

Shell, D. F., Brooks, D.W., Trainin, G., Wilson, K.M., Kauffman, D.F., \& Herr, L.M. (2010). The unified learning model: How motivational, cognitive, and neurobiological sciences inform best teaching practices. New York, NY: Springer.

Sibley, D. F. (2005). Visual abilities and misconceptions about plate tectonics. Journal of Geoscience Education, 53, 471-477.

Simms, J. L., Kusenbach, M., \& Tobin, G.A. (2013). Equally unprepared: Assessing the hurricane vulnerability of undergraduate students. Weather, Climate, and Society, 5(3), 233-243.

Simons, T. (1993). Speech patterns and the concept of utility in cognitive maps: The case of integrative bargaining. Academy of Management Journal, 36, 139-156.

Smith, G. A., \& Bermea, S. B. (2012). Using students' sketches to recognize alternative conceptions about plate tectonics persisting from prior instruction. Journal of Geoscience Education, 60(4), 350-359.

Smith, T. M. F. (1983). On the validity of inferences from non-random sample. Journal of the Royal Statistical Society. Series A (General), 146, 394-403.

Stone, A. A., Turkkan, J. S., Bachrach, C. A., Jobe, J. B., Kurtzman, H. S., \& Cain, V. S. (Eds.). (2000). The science of selfreport: Implications for research and practice. Mahwah, NJ: Lawrence Erlbaum Associates.

Strauss, A., \& Corbin, J. (1990). Basics of qualitative research: Grounded theory procedures and techniques. Newbury Park, California: Sage. 
US Global Change Research program. (2009). Climate Literacy: The Essential Principles of Climate Science Version 2. Available at http://cpo.noaa.gov/sites/cpo/Documents/pdf/ClimateLiteracyPoster-8_5x11_Final4-11LR.pdf (accessed 28 July 2010).

Vosniadou, S., \& Brewer, W. F. (1992). Mental models of the Earth: A study of conceptual change in childhood. Cognitive Psychology, 24, 535-585.

Vosniadou, S. (1994). Capturing and modeling the process of conceptual change. Learning and Instruction, 4, 45-69.

Wuebbles, D. J., Kunkel, K., Wehner, M., \& Zobel, Z. (2014). Severe Weather in United States under Changing Climate. EOS, 95(18), 149-156.

Wieman, C., \& Perkins, K. (2005). Transforming physics education. Physics Today, 58(11), 36-41.

Wieman, C. (2007). Why not try a scientific approach to science education? Change, 39(5), 9-15.

Westgate, K. (1978). Hurricane response and hurricane perception in the Commonwealth of the Bahamas. Mass Emergencies, 3 , 251-265.

Wysession, M., Taber, J., Budd, D. A., Campbell, K., Conklin, M., LaDue, N., Lewis, G., Raynolds, R., Ridky, R., Ross, R., Tewksbury, B., \& Tuddenham, P. (2009). Earth Science Literacy Principles: The Big Ideas and Supporting Concepts of Earth Science. Available at http://eo.ucar.edu/asl/pdfs/es_literacy_brochure.pdf (accessed 1 August 2010).

Wysession, M. (2012). Implications for Earth and space in new K-12 science standards. EOS, 93(46), 465-472.

Yeaton, W. H., \& Worton, P. M. (1993). On the reliability of meta-analytic reviews: The role of intercoder agreement. Evaluation Review, 17(3), 292-309.

Zelditch, M. Jr. (1962). Some methodological problems of field studies. The American Journal of Sociology, 67, $566-576$.

Zhang, F., Morss, R. E., Sippel, J. A., Beckman, T. K., Clements, N. C., Hampshire, N. L., Harvey, J. N., Hernandez, J. M., Morgan, Z. C., Mosier, R. M., Wang, S., \& Winkley, S. D. (2007). An in-person survey investigating public perceptions of and responses to Hurricane Rita forecasts along the Texas coast. Weather Forecasting, 22, 1177-1190. 
NOTES 